This document is published in:

L. Bolzoni, P.G. Esteban, E.M. Ruiz-Navas and E. Gordo, Mechanical Behaviour of Pressed and Sintered Titanium Alloys Obtained from Master Alloy Addition Powders, Journal of the Mechanical Behavior of Biomedical Materials, Nov. 2012, v. 15, 3345, http://dx.doi.org/10.1016/j.jmbbm.2012.05.019

(C) Elsevier 2012 


\title{
Mechanical Behaviour of Pressed and Sintered Titanium Alloys Obtained from Master Alloy Addition Powders
}

\author{
*L. Bolzoni, P.G. Esteban, E.M. Ruiz-Navas, E. Gordo \\ Departamento de Ciencia e Ingeniería de Materiales e Ingeniería Química \\ Universidad Carlos III de Madrid \\ Avda. de la Universidad, 30, 28911 Leganés (Madrid), Spain \\ *e-mail: lbolzoni@ing.uc3m.es
}

\begin{abstract}
The fabrication of the workhorse Ti-6Al-4V alloy and of the Ti-3Al-2.5V alloy was studied considering the master alloy addition variant of the blending elemental approach conventionally used for titanium powder metallurgy. The powders were characterised by means thermal analysis and X-ray diffraction and shaped by means of uniaxial pressing. The microstructural evolution with the sintering temperature $\left(900-1400^{\circ} \mathrm{C}\right)$ was evaluated by SEM and EDS was used to study the composition. XRD patterns as well as the density by Archimedes method were also obtained. The results indicate that master alloy addition is a suitable way to fabricate well developed titanium alloy but also to produce alloy with the desired composition, not available commercially. Density of $4.3 \mathrm{~g} / \mathrm{cm}^{3}$ can be obtained where a temperature higher than $1200^{\circ} \mathrm{C}$ is needed for the complete diffusion of the alloying elements. Flexural properties comparable to those specified for wrought Ti-6Al-4V medical devices are, generally, obtained.
\end{abstract}

Keywords: Ti-3Al-2.5V, Ti-6Al-4V, titanium P/M, blending elemental (BE), master alloy, flexural properties

\section{Introduction}

Titanium is characterised by a combination of properties which differentiate it and that can be resumed in three main features. The first one is the relatively low density, being a $40 \%$ lighter than steel, making it a light metal (Leyens and Peters, 2003). Titanium presents strength comparable to that of steel; this aspect combine with the low density makes it the structural metal with the highest specific strength being more efficient in terms of weight/volume ratio and, therefore, resulting in a lighter structural component compared to steel or the other light alloy such as aluminium and magnesium with similar mechanical strength (Lütjering and Williams, 2003). Moreover, the high strength combined with the low elastic modulus, half of 
that of steel, results in a superior toughness or modulus of resilience (Russell and Lee, 2005). Third, titanium is highly reactive with oxygen forming a passivation layer which confers it an excellent corrosion resistance in many aggressive environments as well as an outstanding biocompatibility and, thus, suitable for the production of medical prosthesis. Even though of its mechanical properties and chemical stability, titanium is still mainly employed in highdemanding industries and not in high productive sector such as the automotive. The application of the powder metallurgy $(\mathrm{P} / \mathrm{M})$ route should lead to a decrement of the production cost of titanium which represents one of the mayor limiting factors for its spreading and avoid segregation of non toxic but heavy alloying elements such as $\mathrm{Nb}, \mathrm{Zr}$ or Ta (Niinomi, 2002). Nowadays, the availability of cleaner starting powder compared to sponge fines, whose chlorides can cause problem during sintering hindering the closure of the residual porosity, should allow to obtain components with better performances. The two classical titanium $\mathrm{P} / \mathrm{M}$ approaches are the prealloyed (PA) and the blending elemental (BE) route where this last one appears to be one of the most promising to produce low-cost titanium products (Moxson et al., 1998). Among titanium alloys, the Ti-6Al-4V is known as the workhorse of the titanium industry being used in many advanced applications, especially aerospace and military, while the Ti-3Al-2.5V is mainly used to attain tubular products for aircraft hydraulic and fuel systems although, lately, it has been considered for the fabrication of sports equipments as well as medical and dental products (Boyer et al., 1998). Until recently, the main approach taken for the introduction of orthopaedic materials has involved adaptation of existing materials (Dewidar et al., 2006) and, therefore, there are not studied about the production of the Ti-3Al-2.5V alloy by conventional P/M. Lately, the Ti-3Al-2.5V has been processed by conventional (Bolzoni et al., 2012a) and inductive hot-pressing (Bolzoni et al., 2012b) to produced fully dense materials. The aim of this work is to study the fabrication of the previously mentioned titanium alloys by means of the conventional $\mathrm{P} / \mathrm{M}$ route of pressing and sintering considering the master alloy addition approach, a variant of the $\mathrm{BE}$ route, and analyse the microstructural evolution of the alloys with the sintering temperature employed, focusing on the diffusion of the alloying elements to justify the properties obtained.

\section{Experimental Procedure}

For the fabrication of the titanium alloys, a hydride-dehydride (HDH) elemental titanium powder and an $\mathrm{Al}: \mathrm{V}$ master alloy were purchased from GfE Gesellschaft für 
Elektrometallurgie $\mathrm{mbH}$. Some characteristics of the starting powders provided by the supplier are reported in Table 1.

The acquired Al:V (35:65) master alloy was milled in combination with the elemental titanium to reduce the particle size and adjust the composition with elemental aluminium purchased by Sulzer Metco Ltd. The optimised Al:V master alloy has the correct ratio of alloying elements (60:40) and a particle size lower than $63 \mu \mathrm{m}$ (Bolzoni et al., 2011) and was, therefore, blended with elemental titanium in a "turbula" mixer during 30 minutes to obtained the Ti-6Al-4V and Ti-3Al-2.5V alloys. Firstly, the characterisation of the titanium alloy powders was done in terms of differential thermal analysis (DTA), dilatometry and X-ray diffraction (XRD). DTA was carried out by means of a Netzsch STA 449 C Júpiter DTA analyser, under inert atmosphere (Ar), where the loose powder was studied considering a thermal cycle composed of a heating $\left(10^{\circ} \mathrm{C} / \mathrm{min}\right)$ up to $1400^{\circ} \mathrm{C}$, soak time of 15 minutes at temperature and cooling $\left(10^{\circ} \mathrm{C} / \mathrm{min}\right)$. The same thermal cycle was employed for the dilatometric study of green samples which was done by means of a NETZSCH DIL $402 \mathrm{E}$

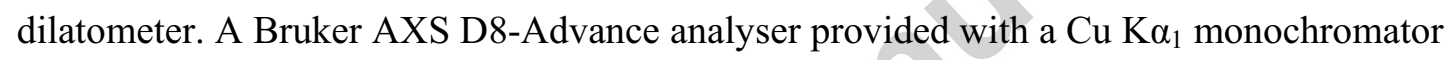
was used for the XRD analysis of the Ti-6Al-4V and Ti-3Al-2.5V powders and of the sintered specimens. The compaction of the powder was carried out with a uniaxial press applying 700 $\mathrm{MPa}$ and using zinc stearate as die wall lubricant for the floating die whereas sintering was done in a high vacuum tubular furnace with a vacuum level of approximately $10^{-5} \mathrm{mbar}$. Heating and cooling rate was fixed at $5^{\circ} \mathrm{C} / \mathrm{min}$ and the dwell time at 2 hours whilst the sintering temperature was ranged between $900^{\circ} \mathrm{C}$ and $1400^{\circ} \mathrm{C}$. The microstructure of the sintered samples was revealed by chemical etching (Kroll's reactant) and analysed by means of scanning electron microscopy in BSE mode while the distribution of the alloying elements was checked by EDS. The mechanical characterisation of the sintered samples was done by the three-point bending tests (ASTM B528) in order to measure the strength and the strain and hardness measurement.

\section{Results and Discussion}

\subsection{XRD analysis of the powders}

The results of the XRD analysis carried out on the starting powder are shown in Figure 1. Regarding the XRD of the Ti-6Al-4V alloy (Figure $1 \mathrm{a}$ ), in the powder were identified all the elements used to prepare it. More in detail, they are titanium $\alpha$ phase, due to the HDH elemental titanium powder, elemental aluminium, and aluminium/vanadium phase labelled as 
$\mathrm{Al}_{2} \mathrm{~V}_{3}$ due to the master alloy employed during the production of the powder. It is worth mentioning that the main peak of aluminium coincides with the second most intense peak of the titanium $\alpha$ phase $\left(002\right.$ at $\left.38.4^{\circ}\right)$. This is the reason why the relative intensity of the main peak of the $\alpha$ phase $\left(101\right.$ at $\left.40.1^{\circ}\right)$ is not the highest as expected and as it is for the Ti-3Al$2.5 \mathrm{~V}$ powder (Figure $1 \mathrm{~b}$ ). This and the lower relative intensity of the peak of the $\mathrm{Al}_{2} \mathrm{~V}_{3}$ phase are the only differences between the XRD pattern of the two alloys and are mainly due to the amount of alloying elements added to the HDH elemental titanium powder.

\subsection{Differential Thermal Analysis (DTA)}

As it has been said, DTA was performed on loose powder and the results, represented as heating curves, are shown Figure 2.

From the DTA heating curves shown in Figure 2, it can be seen that three main reactions take place during the sintering of the titanium alloy powders produced considering the master alloy addition approach. The first endothermic peak at approximately $330^{\circ} \mathrm{C}$ corresponds to the elimination of the wax used as process control agent during milling of the purchased $\mathrm{Al}: \mathrm{V}$ (35:65) master alloy. The details of the reaction, namely the onset temperature and the top of the peak, are reported in Table 2.

The second endothermic peak near $900^{\circ} \mathrm{C}$ corresponds to the $\alpha$ to $\beta$ allotropic transformation. This temperature results to be lower than the nominal $\beta$ transus (see Table 2) of the titanium alloys considered and it is due to the powder production method, therefore, the endothermic peak detected corresponds to that of the elemental titanium powder which is, further, confirmed by the onset temperature and by the top of the peak that coincide with those found for the HDH titanium powder (Bolzoni et al., 2012c). The exothermic peak detected at $660^{\circ} \mathrm{C}$ is due to some kind of interaction between elemental titanium and the elemental aluminium added to the powders in order to reach the desired composition and, precisely, corresponds to the formation of the intermetallic $\mathrm{TiAl}_{3}$ (Böhm and Kieback, 1998).

\section{$\underline{3.3 \text { Dilatometric study }}$}

The results of the dilatometric study, shrinkage versus temperature, are displayed in Figure 3 whilst Table 3 reports the maximum length variation and the onset temperature.

As it can be seen in Figure 3, the shrinkage behaviour of the two titanium alloys studied is similar, since the onset temperature is approximately $820^{\circ} \mathrm{C}$ for both of them, but the maximum shrinkage is higher for the Ti-3Al-2.5V powder even though of the similar green density $(86 \%)$. From this, it seems that the lower the amount of the alloying elements that 
have to diffuse to reach a homogeneous microstructure the higher the shrinkage obtained, which could indicate that a great among of the thermal energy available in the system is invested in diffusion processes instead of in the densification of the green compact. Moreover, the mean shrinkage rate is greater for Ti-3Al-2.5V alloy $\left(1.61 \times 10^{-4} \mathrm{o}^{-1}\right)$ than for Ti-6Al-4V $\left(1.31 \times 10^{-4}{ }^{\circ} \mathrm{C}^{-1}\right)$, once again most probably due to the higher percentage of alloying elements. A remarkable feature of the dilatometric curves is the swelling of the samples, between $0.4 \%$ and $1 \%$ depending on the alloy considered, which starts at $500^{\circ} \mathrm{C}$ and culminates at approximately $620^{\circ} \mathrm{C}$, as it can be seen in Figure 4 which displays the dilatometric behaviour of the powder between $500^{\circ} \mathrm{C}$ and $900^{\circ} \mathrm{C}$.

As it can be seen in Figure 4, starting form $500^{\circ} \mathrm{C}$, the $\mathrm{dL} / \mathrm{L}_{0}$ parameter of the alloys obtained by master alloy addition titanium alloys increases exponentially until $620^{\circ} \mathrm{C}$ and, then, it starts to decrease. This effect is due to the diffusion of the elemental aluminium added during the production of the titanium alloys which reacts with elemental titanium forming the $\mathrm{TiAl}_{3}$ intermetallic, as the results of the DTA analysis indicates (Figure 2), and induces a small swelling of the $\mathrm{P} / \mathrm{M}$ component before it starts to sinter. It is worth mentioning that the height of the peaks shown in Figure 4 is proportional to the percentage of elemental aluminium added to adjust the final composition where the greater the amount of elemental Al, the higher the swelling of the samples.

\section{$\underline{3.4 \text { Microstructural evolution during sintering of the Ti-6Al-4V alloy }}$}

Figure 5 shows the microstructural evolution of the Ti-6Al-4V alloy during vacuum sintering ranging the temperature between $900^{\circ} \mathrm{C}$ and $1400^{\circ} \mathrm{C}$.

As it can be seen in Figure 5, at a sintering temperature of $900^{\circ} \mathrm{C}$ (Figure 5 a) the interparticle necking between the powder particles has already started in agreement with the results of the dilatometric study (Figure 3) where the onset temperature is approximately $820^{\circ} \mathrm{C}$ (Table 3 ).

By the way, some of the interparticle boundaries are still visible, especially in correspondence of the master alloy particles and, therefore, the pore structure is mainly angular and interconnected. Moreover, some small two-phase $\alpha+\beta$ islands are distributed throughout the microstructure and most probably in zones where the amount of vanadium diffused through the titanium matrix is locally high enough to induce the stabilisation of the $\beta$ phase since the processing temperature is far below the nominal $\beta$ transus of this alloy.

The composition change was analysed by EDS in the vicinity of a Al:V master alloy particle and the results are shown in Figure 6. 
As it can be seen in Figure 6, the EDS chemical analysis in correspondence of the Al:V master alloy particle (position 1) is approximately $80 \mathrm{wt} . \%$ of $\mathrm{V}$ and $20 \mathrm{wt} . \%$ of $\mathrm{Al}$ where the content of vanadium is higher and that of aluminium lower compared to the nominal composition of the brought Al:V master alloy of 35:65 wt.\%. This is due to the faster diffusion of aluminium towards the titanium matrix with respect to vanadium and it is further highlighted by the EDS analysis in the darker zone (position 2), $15 \mu \mathrm{m}$ inside the titanium matrix, where the percentage of aluminium increases to $30 \mathrm{wt} . \%$ whilst that of vanadium drops to $6 \mathrm{wt} . \%$. Moreover, the faster diffusion of aluminium compared to vanadium and titanium leaves some pores inside the master alloy particle (visible in Figure 6) due to the Kirkendall effect. The content of vanadium already found in the titanium matrix, which corresponds to approximately 4.6 at.\%, justifies the presence of two-phase zones since the maximum solubility of vanadium in $\alpha$-Ti about 3 at.\% (Murray, 1987). At $30 \mu \mathrm{m}$ away from the master alloy particle (position 3), it can be seen that there is practically no diffusion of the alloying elements since their percentage is approximately zero and it is due to the lower sintering temperature which does not supply sufficient thermal energy to promote a longer diffusion range.

The increment of the sintering temperature to $1000^{\circ} \mathrm{C}$ induces the reduction of the porosity but the pore structure can be split in two (Figure $5 \mathrm{~b}$ ): isolated and tending to spherical pores from one side and large, angular and interconnected Kirkendall pores near the master alloy particles. This is because this processing temperature is not high enough in order to guarantee the complete diffusion of the alloying elements. Once again, two-phase zones can be distinguished where their size is generally bigger compared to those found at $900^{\circ} \mathrm{C}$. All the features can be clearly distinguished in Figure 7 and the EDS chemical analysis performed in the different coloured zones are reported in Table 4.

From the data shown in Table 4, it can be seen that the chemical composition of the master alloy particles (position 1) remains, practically, unchanged compared to $900^{\circ} \mathrm{C}$ since the ratio between Al:V is 20:80 wt.\%. The EDS analysis of the dark grey zone (position 2) highlights the diffusion of the alloying elements towards the titanium matrix where the faster diffusion of aluminium is clearly visible since the percentage of aluminium is similar to that of the master alloy whilst the amount of vanadium is approximately one third. On the other side, the darkest zone (position 3), it is a much Al richer zone but with very few vanadium as the EDS chemical analysis reveals. This could correspond to the intermetallic that forms during the reaction between the elemental aluminium and elemental titanium at $660^{\circ} \mathrm{C}$ which is decomposing. Anyway, on the base of the literature available, the intermetallic that forms is 
the $\mathrm{TiAl}_{3}$ whereas the composition found seems to resemble much more to the $\mathrm{Ti}_{3} \mathrm{Al}$ since the ratio in atomic percentage of $\mathrm{Ti}: \mathrm{Al}$ found by EDS is, approximately, 65:35 and the compositional range of atomic percentage of aluminium for $\mathrm{Ti}_{3} \mathrm{Al}$ at $1000^{\circ} \mathrm{C}$ ranges between 24 and 37 at. \% (Murray, 1987). Finally, the chemical analysis of the two-phase zone (position 4) confirms that where diffusion has already taken place and the amount of vanadium is locally high enough, the $\beta$ phase gets stabilised.

When selecting a sintering temperature of $1100^{\circ} \mathrm{C}$ (Figure $5 \mathrm{c}$ ), the diffusion of the alloying elements seems to be complete and the microstructure homogenous where $\alpha+\beta$ lamella forms a uniform net distributed throughout the whole microstructure. Furthermore, the pores structure is mainly constituted by more spherical and isolated pores but angular and elongated pores are still present. By the way, the EDS analysis carried out on the sintered specimens, which is shown in Table 5, indicates that the distribution of the alloying elements is not completely uniform because there are zone where the amount of aluminium and vanadium dissolved into the titanium matrix is lower than the expected value.

The increasing of the sintering temperature to $1200^{\circ} \mathrm{C}$ (Figure $5 \mathrm{~d}$ ), $1300^{\circ} \mathrm{C}$ (Figure $5 \mathrm{e}$ ) and $1400^{\circ} \mathrm{C}$ (Figure $5 \mathrm{f}$ ) leads the rounding of the pores, whose total amount decreases, the coarsening of the $\alpha$ phase at the expenses of the $\beta$ phase and to a homogeneous microstructure (Table 5) where the fluctuation of the percentage of the alloying elements are influenced by the relative percentage of the $\alpha$ and $\beta$ phase of the zone analysed.

The results of the chemical analysis performed on $\alpha$ grains and on the $\beta$ lamellae are shown in Table 6.

The EDS chemical analysis of the $\alpha$ and $\beta$ phase reflects the results of the global composition where the fluctuation of the percentage of the alloying elements is due to the limited area of the zones analysed. The amount of vanadium dissolved in the $\alpha$ phase, which is approximately 1.3 at. $\%$, is in agreement with the binary Ti-V phase diagram where the maximum solubility is 3 at.\% and is decreased by the presence of impurities (Murray, 1987). Therefore, not considering the data for the specimens sintered at $1100^{\circ} \mathrm{C}$ where the diffusion phenomena are not completed, the general atomic composition of the two phases can be labelled as $87.9 \mathrm{Ti}-10.7 \mathrm{Al}-1.4 \mathrm{~V}(\alpha)$ and $81.7 \mathrm{Ti}-7.2 \mathrm{Al}-11.1 \mathrm{~V}(\beta)$, respectively. Similar results where obtained when processing the Ti-6Al-4V alloy in the same sintering range but starting from a hydride-dehydride prealloyed Ti-6Al-4V powder (Bolzoni et al., 2012d) further confirming the homogeneity of the alloying elements distribution. Finally, the volume fraction of pores found in the sintered samples decreases from $13.8 \%$ at $900^{\circ} \mathrm{C}$ to $3.4 \%$ at 
$1400^{\circ} \mathrm{C}$ and the porosity changes from irregular and flat at $900^{\circ} \mathrm{C}$ (size distribution between

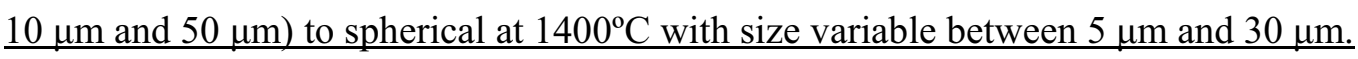

\subsection{Microstructural evolution during sintering of the Ti-3Al-2.5V alloy}

The microstructural evolution of the master alloy addition Ti-3Al-2.5V alloy with the sintering temperature in the range between $900^{\circ} \mathrm{C}$ and $1400^{\circ} \mathrm{C}$ is shown in Figure 8. The sintering of the Ti-3Al-2.5V alloy at a sintering temperature of $900^{\circ} \mathrm{C}$ (Figure 8 a) leads to a microstructure where some interparticle boundaries are still visible, small spherical pores or large and angular pores in correspondence of the master alloy particles are present. Moreover, the diffusion of the alloying elements is not completed and fine two-phase islands can be found. This behaviour is similar to that described for the Ti-6Al-4V alloy but it seems that the amount of spherical pores is greater, the distribution of the alloying elements more homogeneous and the fine $\alpha+\beta$ lamellae less concentrated. This is due to the combination of two factor, the lower amount of alloy elements that have to diffuse, precisely half the quantity of the Ti-6Al-4V alloy, and the fact that a processing temperature of $900^{\circ} \mathrm{C}$ is much nearer to the $\beta$ transus of the alloy than in the case of the Ti-6Al-4V alloy. This is confirmed by the EDS chemical which is detailed in Figure 9.

Analysing the EDS analysis shown in Figure 9, it can be seen that the compositional change trend for the three elements considered, namely aluminium, vanadium and titanium, is similar to that found for the Ti-6Al-4V alloy (Figure 6). Nonetheless, the composition of the Al:V master alloy particle (position 1) is 30:70 wt.\%, instead of 20:80 wt.\% for Ti-6Al-4V, indicating a more uniform diffusion of both the alloying elements. At $25 \mu \mathrm{m}$ from the centre of the master alloy particle (position 2, dark grey coloured), the percentage of aluminium increases to almost $40 \mathrm{wt} . \%$ and that of vanadium falls to $7 \mathrm{wt} . \%$, being both of them higher than the values found in the Ti-6Al-4V alloy.. Once again, the amount of vanadium already diffused in the titanium matrix is higher than the maximum solubility of vanadium in the $\alpha$ phase (3 at.\%) and, therefore, this leads to the stabilisation of two-phase zones.

Consequently, the behaviour of the two alloys at $1000^{\circ} \mathrm{C}$ is similar but the differences in terms of dishomogeneity of the distribution of the alloying elements, amount of spherical pores and volume fraction of two-phase islands are maintained. As for the Ti-6Al-4V alloy, the diffusion of the alloying elements seems to be complete at $1100^{\circ} \mathrm{C}$ for the Ti-3Al-2.5V alloy but, conversely, practically only spherical pores are present and the $\beta$ phase is confined at the $\alpha$ grain boundaries. Once again, a further increment of the sintering temperature induces the reduction of the total amount of residual porosity, the rounding of the pores, which are mainly 
located at the grain boundaries, and the growth of the mean $\alpha$ grain size. The results of the composition, determined by EDS, as a function of the sintering temperature sintering from $1100^{\circ} \mathrm{C}$ to $1400^{\circ} \mathrm{C}$ is presented in Table 7 .

The results of the analysis shown in Table 7 indicates that the materials reaches a homogeneous distribution of the alloying elements starting from $1200^{\circ} \mathrm{C}$ whereas with a sintering temperature of $1100^{\circ} \mathrm{C}$ there are still zone where amount of aluminium is slightly higher and that of vanadium somewhat lower compared to the nominal composition of $3 \mathrm{wt} . \%$ of aluminium and $2.5 \mathrm{wt} . \%$ of vanadium. This behaviour was already found for the Ti-6Al-4V alloy but it is less remarkable for the Ti-3Al-2.5V alloy due to the lower amount of alloying elements. EDS chemical analysis performed on the two phases that constitutes the material resembles that of the Ti-6Al-4V alloy but are, proportionally, lower and the atomic composition is $92.8 \mathrm{Ti}-6.3 \mathrm{Al}-0.9 \mathrm{~V}$ and $89.6 \mathrm{Ti}-4.8 \mathrm{Al}-5.6 \mathrm{~V}$ for $\alpha$ and $\beta$, respectively. These percentages are similar to those found when producing the Ti-3Al-2.5V alloy starting from the blending of elemental titanium and a prealloyed Ti-6Al-4V powder (Bolzoni et al., $2012 \mathrm{~d}$ ). Concerning the volume fraction of pores found in the Ti-3Al-2.5V alloy samples, this is slightly lower than the one found in the Ti-6Al-4V specimens since it decreases from

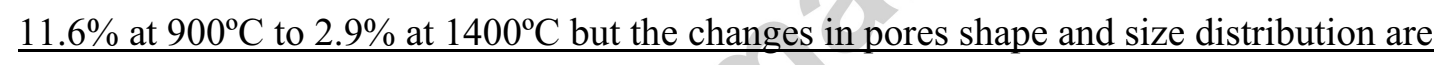
$\underline{\text { similar. }}$

\section{$\underline{3.6 \mathrm{XRD} \text { analysis of the sintered materials }}$}

$\mathrm{X}$-rays analysis was performed on the sintered specimens to identify the phase that constitute them and the results are displayed in Figure 10.

As it can be seen in Figure 10 a), the phases detected in the specimens made out from the master alloy addition Ti-6Al-4V powder sintered at $900^{\circ} \mathrm{C}$ are the titanium $\alpha$ phase and some $\mathrm{Al}_{2} \mathrm{~V}_{3}$, phase which was already detected in the starting powder (Figure $1 \mathrm{a}$ ) and corresponds to the master alloy. Nonetheless, in the starting powder also the peaks which correspond to elemental aluminium were identified whilst in the sintered specimens has already disappeared. This is in agreement with the results of the dilatometric study (Figure 3) which indicates that elemental aluminium reacts with elemental titanium forming the $\mathrm{TiAl}_{3}$ intermetallic, as explained on the base of the DTA analysis (Figure 2). The XRD pattern of the specimens sintered at $1100^{\circ} \mathrm{C}$ confirms what supposed from the microstructural analysis (Figure $5 \mathrm{c}$ ), that the diffusion of the alloying elements is practically completed since no $\mathrm{Al}_{2} \mathrm{~V}_{3}$ phase could be found. Moreover, in the XRD pattern a very low intense peak which corresponds to the $\beta$ phase was detected. The result of the increasing of the sintering 
temperature, which can be seen in the XRD pattern of the specimens sintered at $1300^{\circ} \mathrm{C}$ (Figure 10 a), is substantially an increment of the intensity of the peak of the $\beta$ phase which could indicate that its volume fraction increases.

The same behaviour described for the Ti-6Al-4V alloy can be applied to explain the evolution of the phase for the Ti-3Al-2.5V powder (Figure $10 \mathrm{~b}$ ) but there are two main differences: the relative intensity of the $\mathrm{Al}_{2} \mathrm{~V}_{3}$ phase found in the specimens sintered at $900^{\circ} \mathrm{C}$ and the relative intensity of the $\beta$ phase in the specimens where the diffusion processes are already completed are lower due to smaller amount of alloying elements for the first case and to the lower amount of $\beta$ stabilising for the second. Actually, the peak corresponding to the $\beta$ phase was not detected in the specimens sintered at $1100^{\circ} \mathrm{C}$ as shown in Figure $10 \mathrm{~b}$ ). Finally, although of the formation of the $\mathrm{TiAl}_{3}$ intermetallic at approximately $660^{\circ} \mathrm{C}$, whose volume fraction should increase with the amount of elemental aluminium since it corresponds to a greater swelling of the samples (Figure 4), no such phase was detected during X-ray analysis either in the Ti-3Al-2.5V alloy or in the Ti-6Al-4V alloy, where the probability is greater. This could be either due to the fact that the intermetallic dissolves during the sintering of the powder or that its volume fraction is lower than the detection limit of X-ray diffraction.

\subsection{Density of sintered materials}

The variation of the density of the specimens made out of master alloy addition Ti-6Al-4V and Ti-3Al-2.5V powders is presented in Figure 11.

The final density of the sintered specimens made out of master alloy addition Ti-6Al-4V and Ti-3Al-2.5V powders (Figure 11) have the same increasing trend and, therefore, the greatest densification of the materials takes place at the lower temperature, especially from $900^{\circ} \mathrm{C}$ to $1200^{\circ} \mathrm{C}$, and then it increases at a lower rate. This behaviour is in agreement with the respective microstructural evolution of the Ti-6Al-4V (Figure 5) and of the Ti-3Al-2.5V alloy (Figure 6) since at $1200^{\circ} \mathrm{C}$ the pore structure is already composed of spherical and isolated pores (second stage of sintering) and a further increment of the sintering temperature induces the coarsening of both the pores and the mean $\alpha$ grain size. Nonetheless, it can be noticed that the gap between the two curves narrows with the increasing of the sintering temperature which is mainly due to the different amount of thermal energy invested for diffusion processes and homogenisation of the composition and, thus, subtracted to the densification of the material which results to be more important at the lower processing temperatures. Besides, a contribution from the greater amount of $\mathrm{TiAl}_{3}$ intermetallic that forms in Ti-6Al-4V alloy compared to Ti-3Al-2.5V, which could hinder the consolidation of powder metallurgy 
titanium alloys (Böhm and Kieback, 1998; Ivasishin, 2005), can not be discharged, even though this compound was not detected during XRD analysis. The corresponding relative density values of the data shown in Figure 11, which varies approximately from $86.2 \%$ to $96.6 \%$ of the theoretical density for Ti-6Al-4V and from $88.4 \%$ to $97.1 \%$ of the theoretical density for Ti-3Al-2.5V, are similar to those found for other titanium alloys using the same processing route (Bolzoni et al., 2012c; Bolzoni et al., 2012d).

\subsection{Mechanical characterisation}

The typical behaviour of the P/M Ti-6Al-4V and Ti-3Al-2.5V samples during the three-point bending tests is presented in Figure 12 as load-deflection curves for the sintering temperature of $1000^{\circ} \mathrm{C}, 1200^{\circ} \mathrm{C}$ and $1400^{\circ} \mathrm{C}$.

From the load-deflection curves shown in Figure 12 it can be seen that the elastic deformation of the specimens made out of Ti- $6 \mathrm{Al}-4 \mathrm{~V}$ and Ti-3Al-2.5V is the same indicating that the two materials have similar flexural modulus. Nevertheless, there is an important difference between the behaviour of these two alloys because Ti-6Al-4V samples break without any appreciable plastic deformation whilst Ti-3Al-2.5V specimens deforms plastically before fracture, especially visible in the load-deflection curve of the samples sintered at $1200^{\circ} \mathrm{C}$ (Figure 12 b). This behaviour reflects in a different fracture mode as it can be observed by analysing the fracture surface of the samples reported on the right part of the load-deflection curves. More in detail, the fracture of the Ti-3Al-2.5V samples sintered at $1000^{\circ} \mathrm{C}$ (Figure 12 a) occurs by grain-boundary separation, typical of the intercrystalline fracture, whereas that of Ti-6Al-4V specimens is a mixed intercrystalline and transcrystalline cleavage fracture due to both grain-boundary separation and river marking formation within the grain. This same fracture mechanism can be applied to the materials sintered at $1200^{\circ} \mathrm{C}$ but with the difference that the transcrystalline component acting in the Ti-6Al-4V samples is greater, which helps to explain the greater difference in terms of load-deflection curve found between Ti-6Al-4V and Ti-3Al-2.5V samples (Figure $12 \mathrm{~b}$ ). Concerning the specimens sintered at $1400^{\circ} \mathrm{C}$, it can be seen that, accordingly to the similar load-deflection curves, the two alloys fail by transcrystalline cleavage fracture.

The equation for the calculation of transverse rupture strength specified in the ASTM B528 standard is valid only for relatively brittle materials but, as just indicated, the Ti-3Al-2.5V samples experience plastic deformation before fracture during the three-point bending tests and, thus, the values of the yield strength are taken into account and shown in Figure 13. 
Nonetheless, the maximum bending strength and the deflection to fracture are also plotted in Figure 13.

As it can be seen in Figure 13, the flexural properties (yield strength, maximum bending strength and deflection to fracture) of both materials increases up to a certain sintering temperature, $1200^{\circ} \mathrm{C}$ for Ti- $6 \mathrm{Al}-4 \mathrm{~V}$ and $1300^{\circ} \mathrm{C}$ for Ti-3 Al-2.5V respectively, and then drops down to values comparable to those found for the samples sintered at low temperature $\left(900^{\circ} \mathrm{C}\right.$ and $1000^{\circ} \mathrm{C}$ ). Furthermore, for the flexural strength, it can also be observed that the difference in terms of absolute values increases with the processing temperature being $0 \mathrm{MPa}$ at $900^{\circ} \mathrm{C}$ and $200 \mathrm{MPa}$ for specimens sintered at $1400^{\circ} \mathrm{C}$. The mechanical behaviour just described (load-deflection curve, fracture surfaces and trend of the yield strength) is a direct consequence of the slight differences of final relative density (shape and amount of the residual porosity) and the microstructural evolution of the alloy with the sintering temperature (diffusion of the alloying elements, mean $\alpha$ grain size and relative amount as well as morphology of the $\alpha+\beta$ lamellae). The $\sigma_{0.2}$ and maximum bending strength values shown in Figure 13 are, generally, somewhat higher with respect to the values found when studying the Ti-6Al-7Nb alloy produced by master alloy addition (Bolzoni et al., 2012c) and comparable to those found when processing the Ti-6Al-4V starting from a prealloyed powder (Bolzoni et al., 2012d). On the other side, the yield strength of the blended elemental Ti-3Al-2.5V specimens' results to be always, at least, $50 \mathrm{MPa}$ higher with respect to the strength of master alloy addition Ti-3Al-2.5V samples (Bolzoni et al., 2012d).

Moreover, the maximum yield strength shown in Figure 13 are comparable to those of the master alloy addition Ti-6Al-4V and Ti-3 Al-2.5V alloys processed by vacuum hot-pressing (Bolzoni et al., 2012a; Bolzoni et al., 2012e). Finally, the yield strength and maximum bending strength obtained results also to be higher than the flexural strength specified for wrought Ti-6Al-4V medical devices (903-1090 MPa) (Henry, 2009). In this case, due to the residual porosity and the non homogeneous distribution of the alloying elements, exceptions are the samples sintered at the low temperature $\left(900^{\circ} \mathrm{C}\right.$ and $\left.1000^{\circ} \mathrm{C}\right)$.

The results of the hardness measurements carried out on the cross section of the samples are plotted in Figure 14 versus the sintering temperature.

The hardness of the Ti-6Al-4V and Ti-3Al-2.5V samples (Figure 14) increases continuously with the sintering temperature which is the expected behaviour for $\mathrm{P} / \mathrm{M}$ materials because the higher the sintering temperature the higher the relative density or, conversely, the lower the amount of residual porosity. Moreover, it can also be observed that at low processing temperature the hardness of the two alloys coincide, due to the fact that the alloying elements 
are only partially diffused inside the titanium matrix whereas with the increment of the sintering temperature the difference between the hardness of the two alloys increases. From Figure 14, it can also be seen that P/M Ti-6Al-4V and Ti-3Al-2.5V samples reach an equivalent hardness to those of the respective wrought materials starting from a sintering temperature of approximately $1250^{\circ} \mathrm{C}$ despite of the residual porosity. This is most probably due to the, normally, finer microstructure of $\mathrm{P} / \mathrm{M}$ materials in comparison to that of ingot products and to the amount of interstitials dissolved, such as oxygen, which harden titanium (Jaffee and Campbell, 1949; Jaffee et al., 1950; Finlay and Snyder, 1950).

\section{Conclusions}

Based on the characterisation of the powders produced and on their microstructural evolution with the sintering temperature, it can be concluded that:

- The interaction of elemental titanium with the elemental aluminium generates the $\mathrm{TiAl}_{3}$ intermetallic but this can not be found in the sintered specimens and, therefore, should not influence the properties of the alloy;

- Samples of the master alloy addition Ti-6Al-4V and Ti-3Al-2.5V were fabricated with the cold uniaxial pressing and sintering in vacuum obtaining densities as high as $97 \%$ of the theoretical density;

- For both materials, the typical two-phase microstructure constituted by $\alpha$ grains and $\alpha+\beta$ lamellae was obtained but a sintering temperature of $1200^{\circ} \mathrm{C}$ should be used to promote the complete diffusion of the alloying elements;

- Mechanical properties such as hardness and flexural strength similar to those of the respective wrought materials are, easily, obtained;

- Master alloy addition is a viable method to obtain titanium alloy with the desired composition and could permit to design new alloy for specific applications.

\section{Acknowledgements}

The authors want to acknowledge the financial support from the Spanish Ministry of Science through the R\&D Projects MAT2009-14448-C02-02 and MAT2009-14547-C02-02, and from Regional Government of Madrid through the ESTRUMAT (S2009/MAT-1585) project.

\section{References}


Bolzoni, L., Esteban, P. G., Ruiz-Navas, E. M., Gordo, E., 2011. Influence of Powder Characteristics on Sintering Behaviour and Properties of PM Ti Alloys Produced from Prealloyed Powder and Master Alloy. Powder Metallurgy 54, 543-550.

Bolzoni, L., Ruiz-Navas, Gordo, E., 2012. Vacuum Hot-Pressing of Ti-3Al-2.5V Alloy:

Microstructural Evolution and Mechanical Properties. Materials Chemistry and Physics (Under Review).

Bolzoni, L., Ruiz-Navas, E. M, Neubauer, E., Gordo, E., 2012. Inductive Hot-pressing of

Titanium and Titanium Alloy Powders. Materials Chemistry and Physics 131, 672-679.

Bolzoni, L., Ruiz-Navas, E. M, Weissgaeber, T., Kieback, B., Gordo, E., 2012. Mechanical

Behaviour of Pressed and Sintered CP Ti and Ti-6Al-7Nb Alloy Obtained from Master

Alloy Addition Powder. Journal of Mechanical Behavior of Biomedical Materials, (Under

Review).

Bolzoni, L., Esteban, P. G., Ruiz-Navas, E. M., Gordo, E., 2012. Mechanical Behaviour of

Pressed and Sintered Titanium Alloys Obtained from Prealloyed and Blended Elemental

Powders. Journal of Mechanical Behavior of Biomedical Materials,

DOI:10.1016/j.jmbbm.2012.05.013.

Bolzoni, L., Ruiz-Navas, E. M, Montealegre Meléndez, I., Gordo, E., 2012. Microstructural

Evolution and Mechanical Properties of the Ti-6Al-4V Alloy Produced by Vacuum Hotpressing. Materials Science and Engineering A 546, 189-197.

Böhm and Kieback, 1998. Investigation of Swelling Behaviour of Ti-Al Elemental Powder

Mixtures during Reaction Sintering. Zeitschrift für Metallkunde 89, 90-95.

Boyer, R., Welsch, G., Collings, E. W., 1998. Materials Properties Handbook: Titanium

Alloys, Second ed. ASM-International, Ed. Ohio, USA.

Dewidar, M. M., Yoon, H-C., Lim, J. K., 2006. Mechanical properties of metals for

biomedical applications using powder metallurgy process: A review. Metals and Materials International 12, 193-206.

Finlay W. L. and Snyder, J. A., 1950. Effects of Three Interstitial Solutes (Nitrogen, Oxygen and Carbon) on the Mechanical Properties of High-purity Alpha Titanium. Journal of Metals 188, 277-286.

Henry D., 2009. Materials and Coatings for Medical Devices: Cardiovascular. Ohio, USA,

ASM International, 151-186.

Ivasishin, O. M., 2005. Cost-effective Manufacturing of Titanium Parts with Powder

Metallurgy Approach. Materials Forum 29, 1-8. 
Jaffee, R. I. and Campbell, I. E., 1949. The Effect of Oxygen, Nitrogen and Hydrogen on Iodide Refined Titanium. Transactions of the American Institute of Mining and Metallurgical Engineers 185, 646-654.

Jaffee, R. I., Ogden, H. R., Maykuth, D. J., 1950. Alloys of Titanium with Carbon, Oxygen and Nitrogen. Transactions of the American Institute of Mining and Metallurgical Engineers 188, 1261-1266.

Leyens, C. and Peters, M., 2003. Titanium and Titanium Alloys. Fundamentals and Applications. Köln, Germany, Wiley-VCH, 1-497.

Lütjering, G., Williams, J. C., 2003. Titanium: Engineering Materials and Processes, First ed. Manchester, UK, Springer, 1-356.

Murray, J. L., 1987. Phase Diagrams of Binary Titanium Alloys, First ed, ASM International, $1-345$.

Moxson, V. S., Senkov, O. N., Froes, F. H., 1998. Production and Applications of Low Cost Titanium Powder Products, International Journal of Powder Metallurgy 34, 45-53.

Niinomi, M., 2002. Recent metallic materials for biomedical applications, Metallurgical and Materials Transactions A 33, 477-486.

Russell, A. M. and Lee, K. L., 2005. Structure-property Relations in Nonferrous Metals, Wiley-Interscience, 179-197. 


\section{List of Figure Captions}

Figure 1. X-ray diffraction (XRD) pattern of Ti-6Al-4V (a) and Ti-3Al-2.5V (b) powders.

Figure 2. DTA heating curves for Ti-6Al-4V and Ti-3Al-2.5V titanium alloys.

Figure 3. Master alloy addition Ti-6Al-4V and Ti-3Al-2.5V titanium alloy dilatometric curves.

Figure 4. Details of the $500-900^{\circ} \mathrm{C}$ temperature range of the results of the dilatometric study.

Figure 5. Microstructural evolution of the master alloy addition Ti-6Al-4V alloy sintered under high vacuum: a) $900^{\circ} \mathrm{C}$, b) $1000^{\circ} \mathrm{C}$, c) $1100^{\circ} \mathrm{C}$, d) $1200^{\circ} \mathrm{C}$, e) $1300^{\circ} \mathrm{C}$ and f) $1400^{\circ} \mathrm{C}$.

Figure 6. Details of the diffusion of the alloy elements from an Al:V master alloy particle and relative EDS composition change (distance from position: $15 \mu \mathrm{m}$ ) in the Ti-6Al-4V alloy.

Figure 7. Features that characterise the microstructure of the master alloy addition Ti-6Al-4V alloy sintered at $1000^{\circ} \mathrm{C}$.

Figure 8. Microstructural evolution of the master alloy addition Ti-3Al-2.5V alloy sintered under high vacuum: a) $900^{\circ} \mathrm{C}$, b) $1000^{\circ} \mathrm{C}$, c) $1100^{\circ} \mathrm{C}$, d) $1200^{\circ} \mathrm{C}$, e) $1300^{\circ} \mathrm{C}$ and f) $1400^{\circ} \mathrm{C}$.

Figure 9. Details of the diffusion of the alloy elements from an $\mathrm{Al}: \mathrm{V}$ master alloy particle and relative EDS composition change (distance from position: $25 \mu \mathrm{m}$ ) in the Ti-3Al-2.5V alloy.

Figure 10. XRD patterns for samples sintered at $900^{\circ} \mathrm{C}, 1100^{\circ} \mathrm{C}$ and $1300^{\circ} \mathrm{C}$ : a) blended elemental Ti-6Al-4V alloy and b) blended elemental Ti-3Al-2.5V alloy.

Figure 11. Density versus sintering temperature for the Ti-6Al-4V and Ti-3Al-2.5V alloys obtained by pressing and sintering.

Figure 12. Examples of the typical load-deflection curves obtained during three-point bending tests of Ti-6Al-4V and Ti-3Al-2.5V samples sintered at: a) $1000^{\circ} \mathrm{C}$, b) $1200^{\circ} \mathrm{C}$ and c) $1400^{\circ} \mathrm{C}$. 
Figure 13. Flexural properties, measured by means of three-point bending strength tests, as a function of the sintering temperature for the Ti-6Al-4V and Ti-3Al-2.5V alloys obtained by pressing and sintering: a) yield strength, b) maximum bending strength and c) deflection to fracture.

Figure 14. Hardness versus sintering temperature for the Ti-6Al-4V and Ti-3Al-2.5V alloys obtained by pressing and sintering.

\section{List of Tables}

Table 1. Characteristics of the powders used for the production of the Ti-6Al-4V and Ti-3Al$2.5 \mathrm{~V}$ titanium alloys (supplier specifications).

Table 2. Details of the reactions that take place during the sintering of the Ti-6Al-4V and Ti3Al-2.5V titanium alloys measured on DTA curves.

Table 3. Details of the features detected during the dilatometric analysis of the Ti-6Al-4V and Ti-3Al-2.5V alloys.

Table 4. EDS chemical composition of the features that characterised the microstructure of the master alloy addition Ti-6Al-4V alloy sintered at $1000^{\circ} \mathrm{C}$.

Table 5. Composition determined by EDS as a function of the sintering temperature for the Ti-6Al-4V alloy.

Table 6. EDS chemical composition of the $\alpha$ and the $\beta$ phase of the Ti-6Al-4V alloy as a function of the sintering temperature.

Table 7. Composition determined by EDS as a function of the sintering temperature for the Ti-3Al-2.5V alloy. 
Table 1. Characteristics of the powders used for the production of the Ti-6Al-4V and Ti-3Al$2.5 \mathrm{~V}$ titanium alloys (supplier specifications).

\begin{tabular}{|c|c|c|c|}
\hline Characteristic & Elemental Ti & Al:V & Elemental Al \\
\hline Composition [wt. $\%]$ & $>99.7$ & $35: 65$ & $>99$ \\
\hline Maximum particle size $[\mu \mathrm{m}]$ & $<75$ & $<6300$ & $<150$ \\
\hline Particle morphology & Angular & Granules & Spherical \\
\hline Melting point $\left[{ }^{\circ} \mathrm{C}\right]$ & 1667 & $1650-1725$ & 660 \\
\hline
\end{tabular}


Table 2. Details of the reactions that take place during the sintering of the Ti-6Al-4V and Ti3Al-2.5V titanium alloys measured on DTA curves.

\begin{tabular}{|c|c|c|c|c|}
\hline Alloy & $\begin{array}{c}\text { Onset } \\
\text { temperature }\left[{ }^{\circ} \mathrm{C}\right]\end{array}$ & $\begin{array}{l}\text { Top of the } \\
\text { peak }\left[{ }^{\circ} \mathrm{C}\right]\end{array}$ & Reaction & $\begin{array}{c}\text { Nominal } \beta \\
\text { transus }\left[{ }^{\circ} \mathrm{C}\right]\end{array}$ \\
\hline $\begin{array}{l}\text { Elemental Ti (Bolzoni } \\
\text { et al., 2012c) }\end{array}$ & 875.51 & 904.71 & $\alpha \rightarrow \beta$ & $882 \pm 2$ \\
\hline \multirow{3}{*}{ Ti-6Al-4V } & 325.63 & 339.65 & Wax elimination & \multirow{3}{*}{$996 \pm 15$} \\
\hline & 657.79 & 660.65 & $\mathrm{Ti}+\mathrm{Al}=\mathrm{TiAl}_{3}$ & \\
\hline & 881.45 & 901.23 & $\alpha \rightarrow \beta$ & \\
\hline \multirow{3}{*}{ Ti-3Al-2.5V } & 325.36 & 339.29 & Wax elimination & \multirow{3}{*}{$935 \pm 15$} \\
\hline & 656.82 & 662.97 & $\mathrm{Ti}+\mathrm{Al}=\mathrm{TiAl}_{3}$ & \\
\hline & 880.76 & 907.88 & $\alpha \rightarrow \beta$ & \\
\hline
\end{tabular}


Table 3. Details of the features detected during the dilatometric analysis of the Ti-6Al-4V and Ti-3Al-2.5V alloys.

\begin{tabular}{|c|c|c|}
\hline Alloy & $\begin{array}{c}\text { Maximum } \\
\text { shrinkage [\%] }\end{array}$ & $\begin{array}{c}\text { Onset } \\
\text { temperature }\left[{ }^{\circ} \mathrm{C}\right]\end{array}$ \\
\hline Ti-6Al-4V & -7.69 & 819.2 \\
\hline Ti-3Al-2.5V & -10.18 & 816.4 \\
\hline
\end{tabular}


Table 4. EDS chemical composition of the features that characterised the microstructure of the master alloy addition Ti-6Al-4V alloy sintered at $1000^{\circ} \mathrm{C}$.

\begin{tabular}{|c|c|c|c|}
\hline Position & \multicolumn{3}{|c|}{ Composition [wt.\%] } \\
\hline & $\mathrm{Ti}$ & $\mathrm{Al}$ & $\mathrm{V}$ \\
\hline 1 (Al:V particle) & 2.34 & 20.38 & 77.28 \\
\hline 2 (dark grey zone) & 55.45 & 18.96 & 25.59 \\
\hline 3 (darkest grey zone) & 75.20 & 23.17 & 1.63 \\
\hline 4 (lamellae) & 78.42 & 7.60 & 13.98 \\
\hline
\end{tabular}


Table 5. Composition determined by EDS as a function of the sintering temperature for the Ti-6Al-4V alloy.

\begin{tabular}{|c|c|c|c|}
\hline Temperature $\left[{ }^{\circ} \mathrm{C}\right]$ & \multicolumn{3}{|c|}{ Composition [wt.\%] } \\
\hline & $\mathrm{Ti}$ & $\mathrm{Al}$ & $\mathrm{V}$ \\
\hline 1100 & 92.55 & 4.49 & 2.96 \\
\hline 1200 & 90.40 & 6.07 & 3.53 \\
\hline 1300 & 90.30 & 6.59 & 3.11 \\
\hline 1400 & 89.64 & 6.21 & 4.15 \\
\hline
\end{tabular}


Table 6. EDS chemical composition of the $\alpha$ and the $\beta$ phase of the Ti-6Al-4V alloy as a function of the sintering temperature.

\begin{tabular}{|c|c|c|c|c|c|c|}
\hline Temperature [ ${ }^{\mathbf{0}} \mathbf{C}$ ] & \multicolumn{3}{|c|}{ Composition $\boldsymbol{\alpha}$-phase [at.\%] } & \multicolumn{3}{c|}{ Composition $\boldsymbol{\beta}$-phase [at.\%] } \\
\hline \hline & $\mathrm{Ti}$ & $\mathrm{Al}$ & $\mathrm{V}$ & $\mathrm{Ti}$ & $\mathrm{Al}$ & $\mathrm{V}$ \\
\hline \hline 1100 & 90.42 & 8.22 & 1.36 & 89.90 & 7.26 & 2.84 \\
\hline 1200 & 87.89 & 10.74 & 1.37 & 84.63 & 5.95 & 9.42 \\
\hline 1300 & 87.81 & 11.06 & 1.13 & 82.43 & 8.40 & 9.17 \\
\hline 1400 & 87.93 & 10.45 & 1.62 & 78.04 & 7.19 & 14.77 \\
\hline
\end{tabular}


Table 7. Composition determined by EDS as a function of the sintering temperature for the Ti-3Al-2.5V alloy.

\begin{tabular}{|c|c|c|c|}
\hline Temperature $\left[{ }^{\circ} \mathbf{C}\right]$ & \multicolumn{3}{|c|}{ Composition [wt.\%] } \\
\hline & $\mathrm{Ti}$ & $\mathrm{Al}$ & $\mathrm{V}$ \\
\hline \hline 1100 & 94.09 & 3.61 & 2.30 \\
\hline 1200 & 94.27 & 3.05 & 2.68 \\
\hline 1300 & 94.32 & 3.19 & 2.49 \\
\hline 1400 & 94.12 & 3.45 & 2.43 \\
\hline
\end{tabular}


$>$ The master alloy addition approach to produced titanium alloys is studied. $>$ The diffusion processes that take place to obtain a homogeneous microstructure are analysed. $>$ The microstructural evolution of the alloys with the temperature is evaluated in dept. > Bending properties of PM Ti-6Al.4V and Ti-3Al-2.5V are measured. 

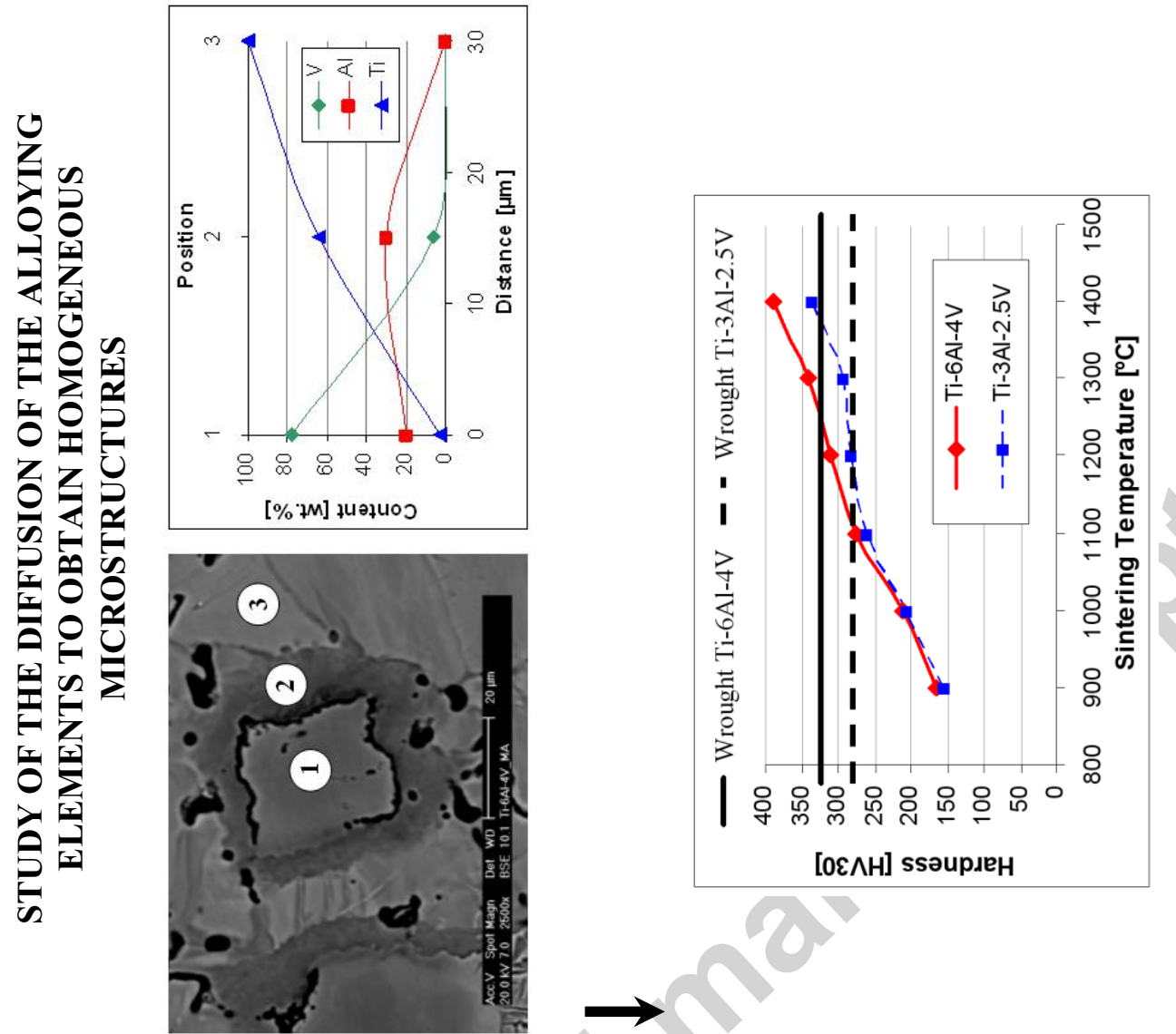

年
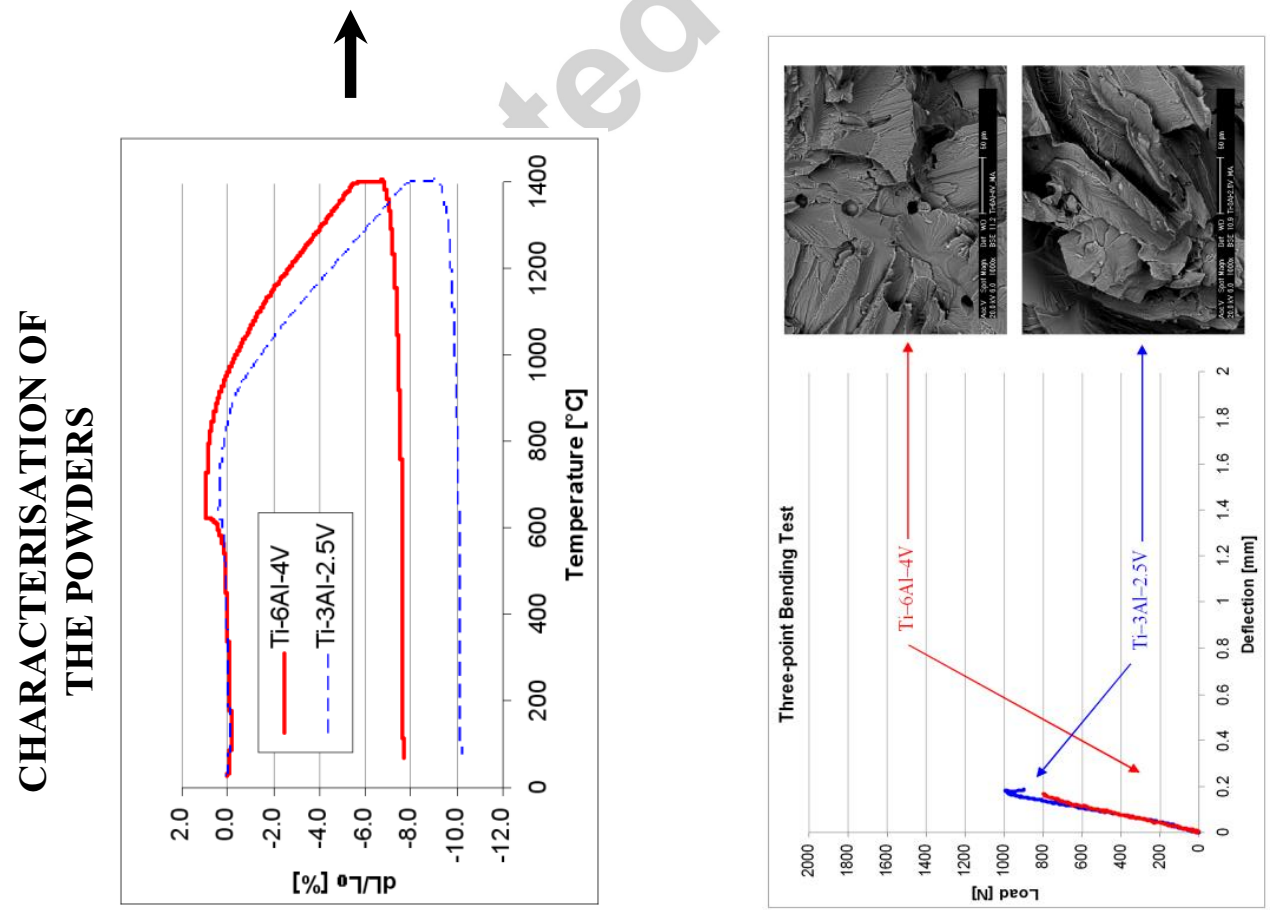


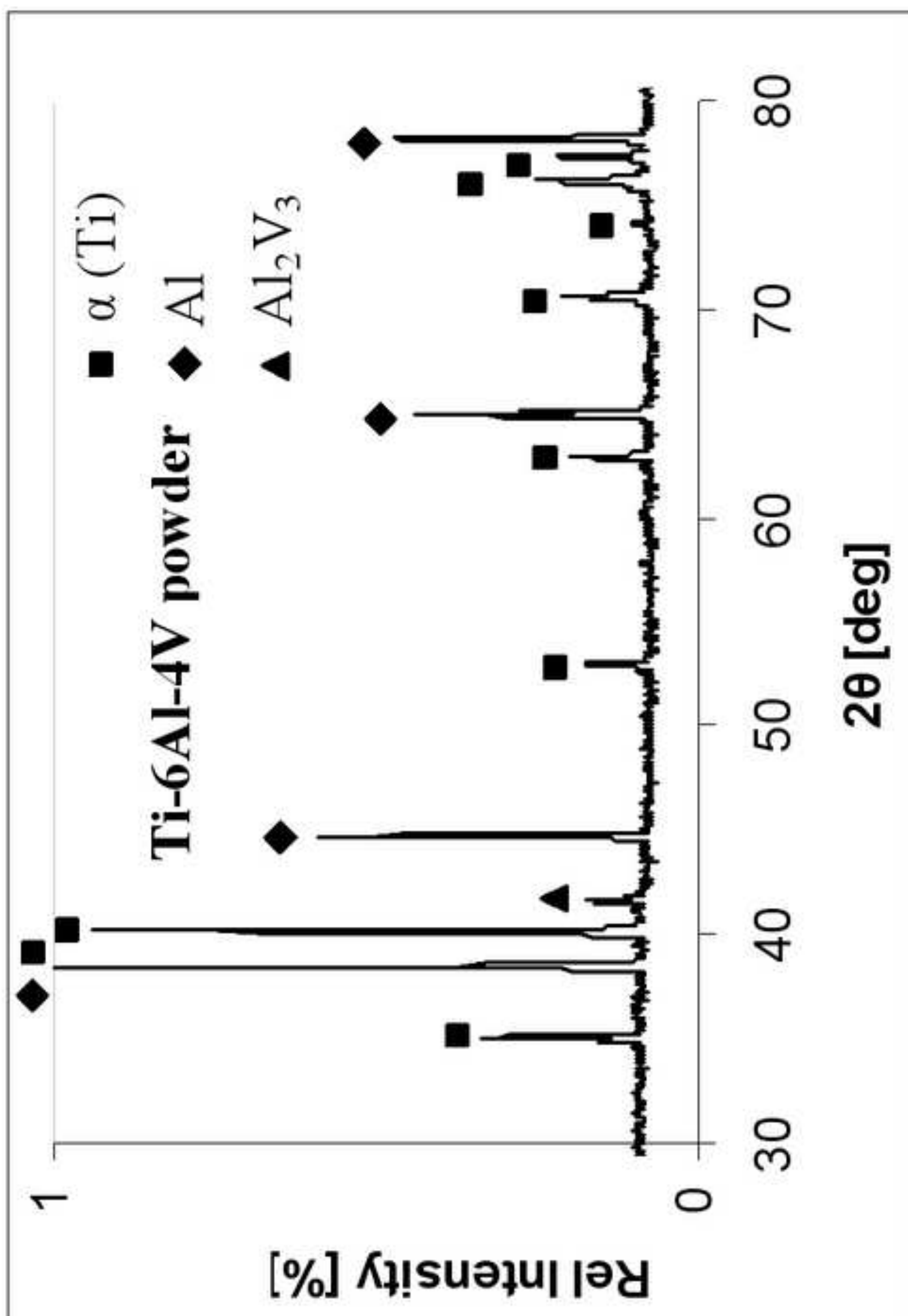




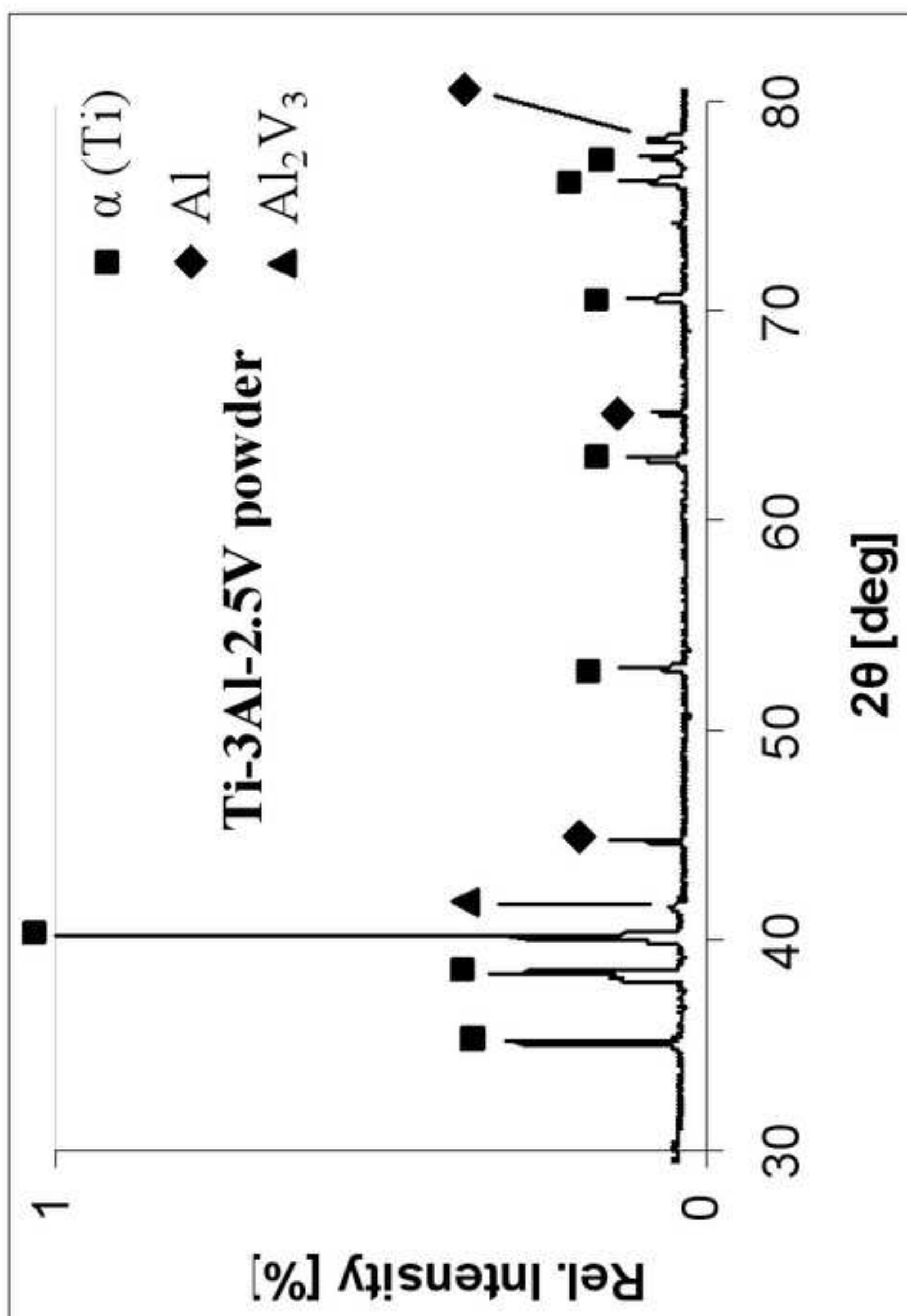

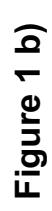




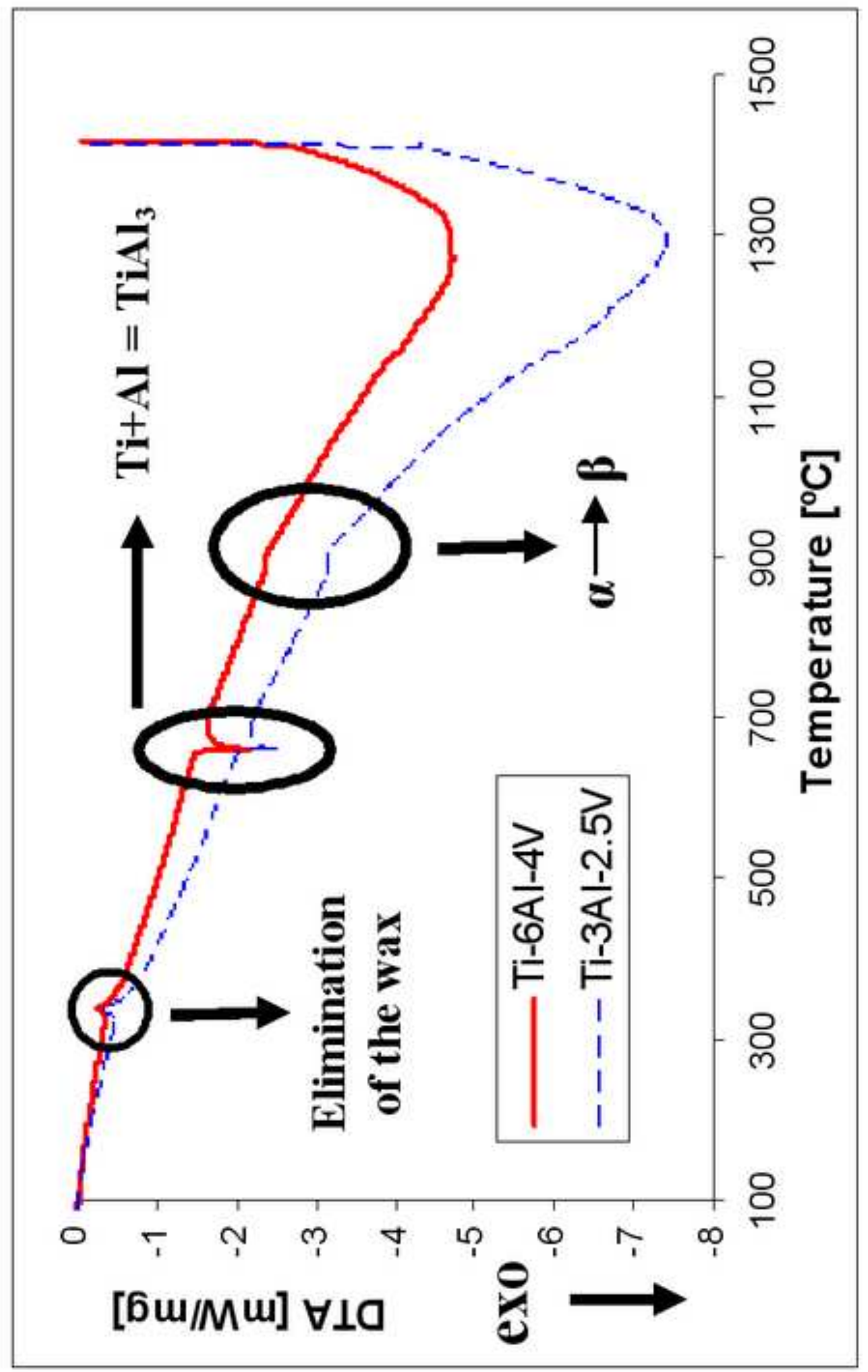




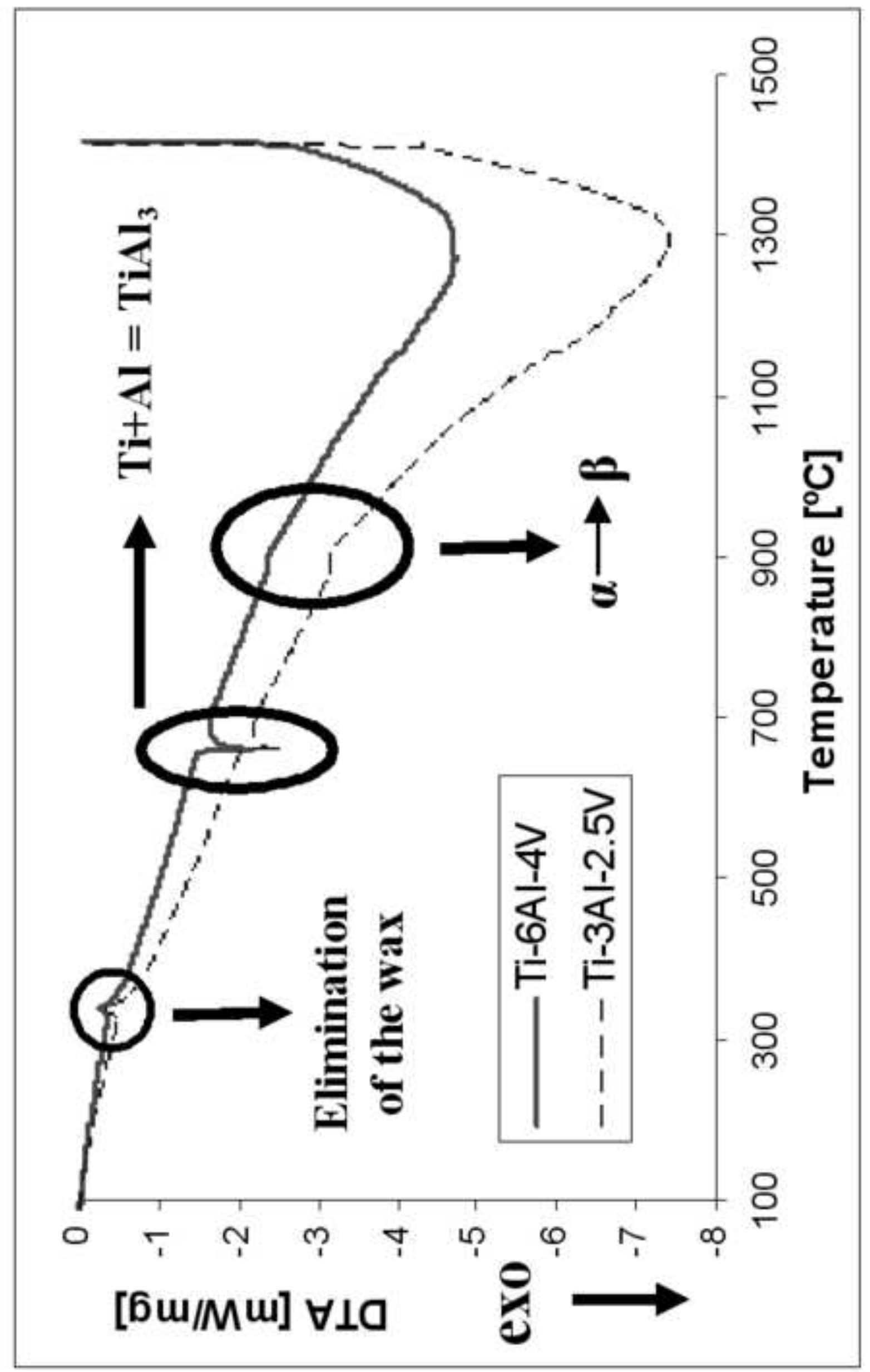




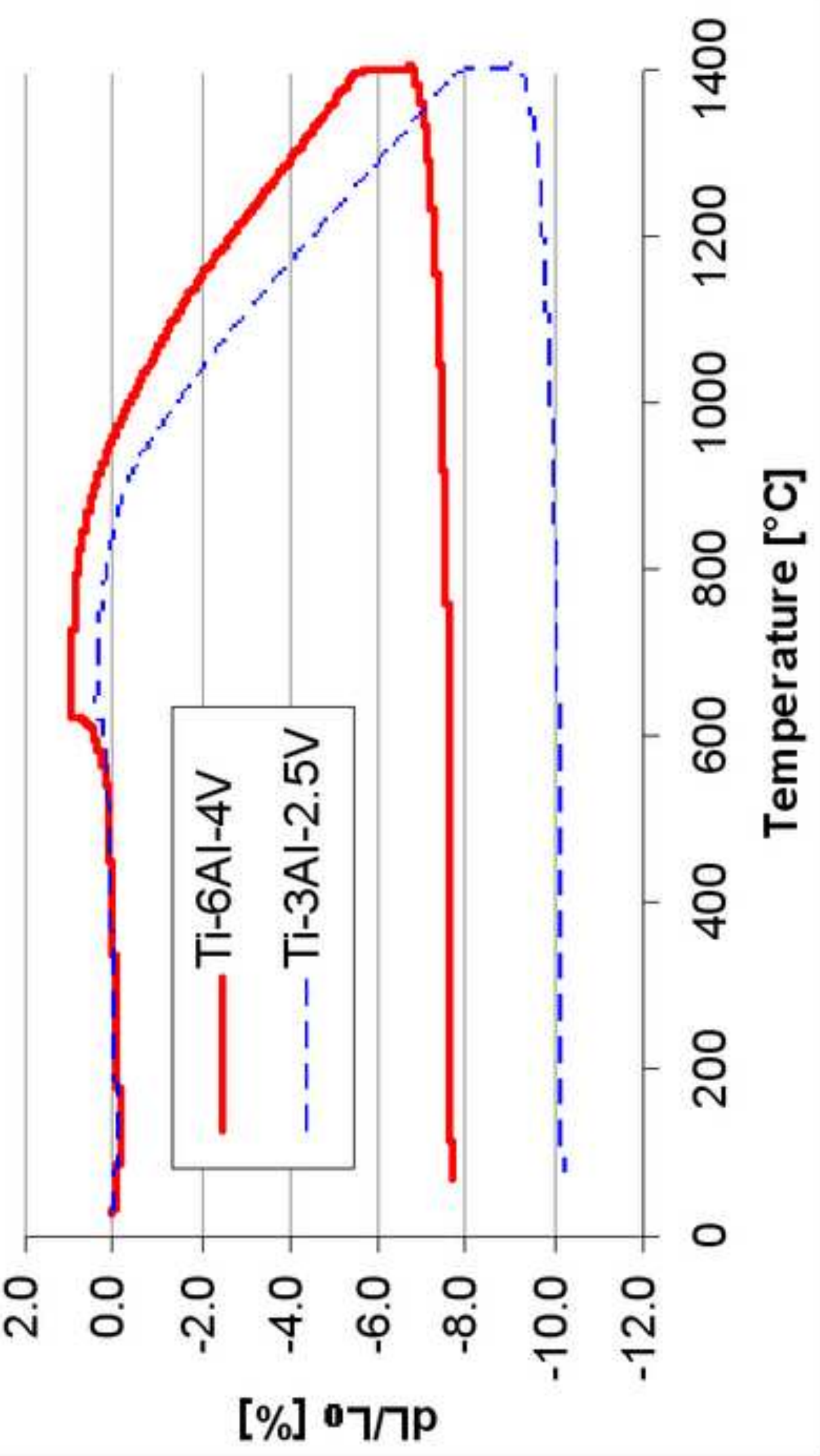

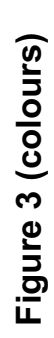




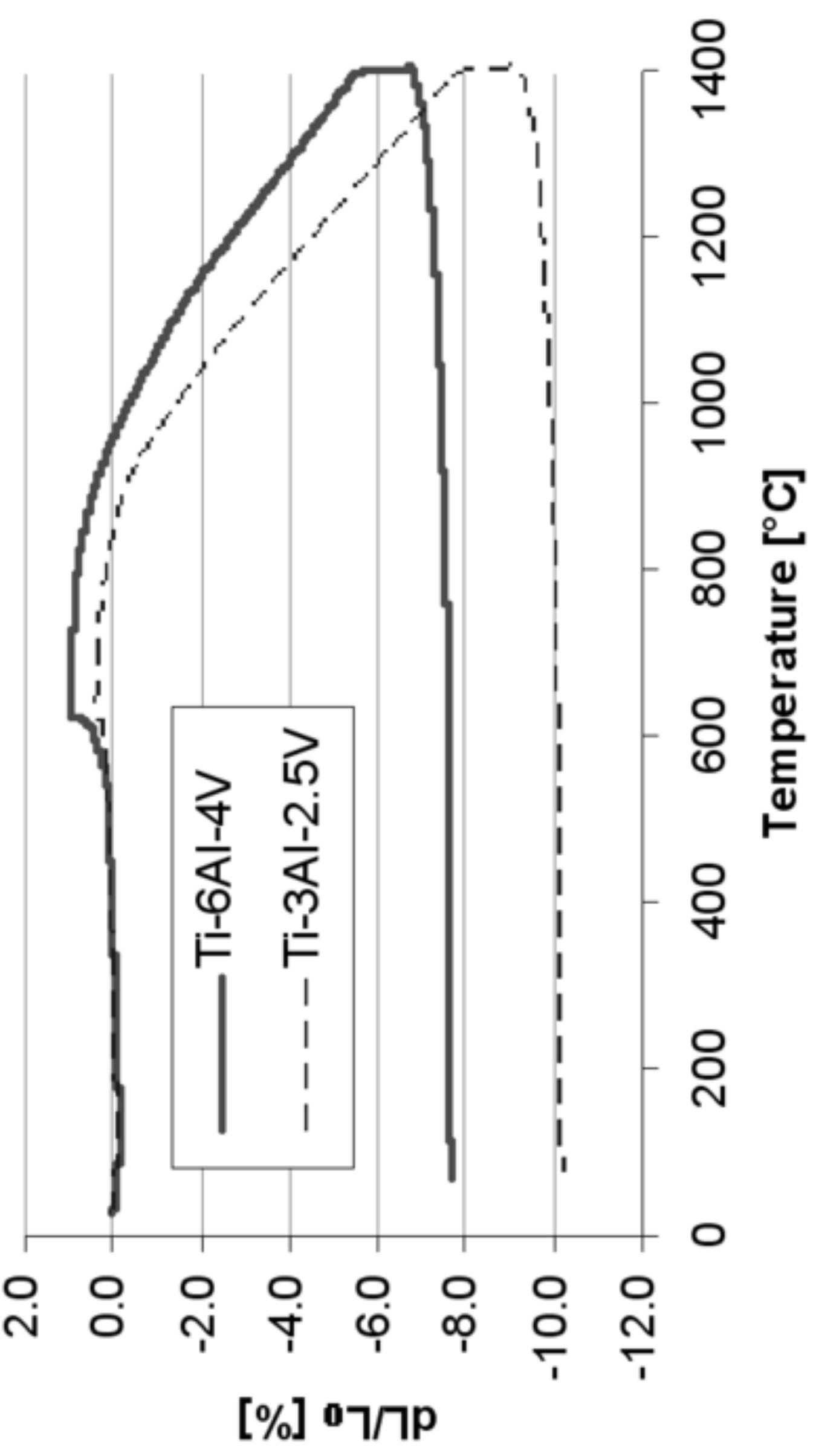

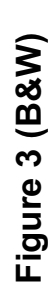




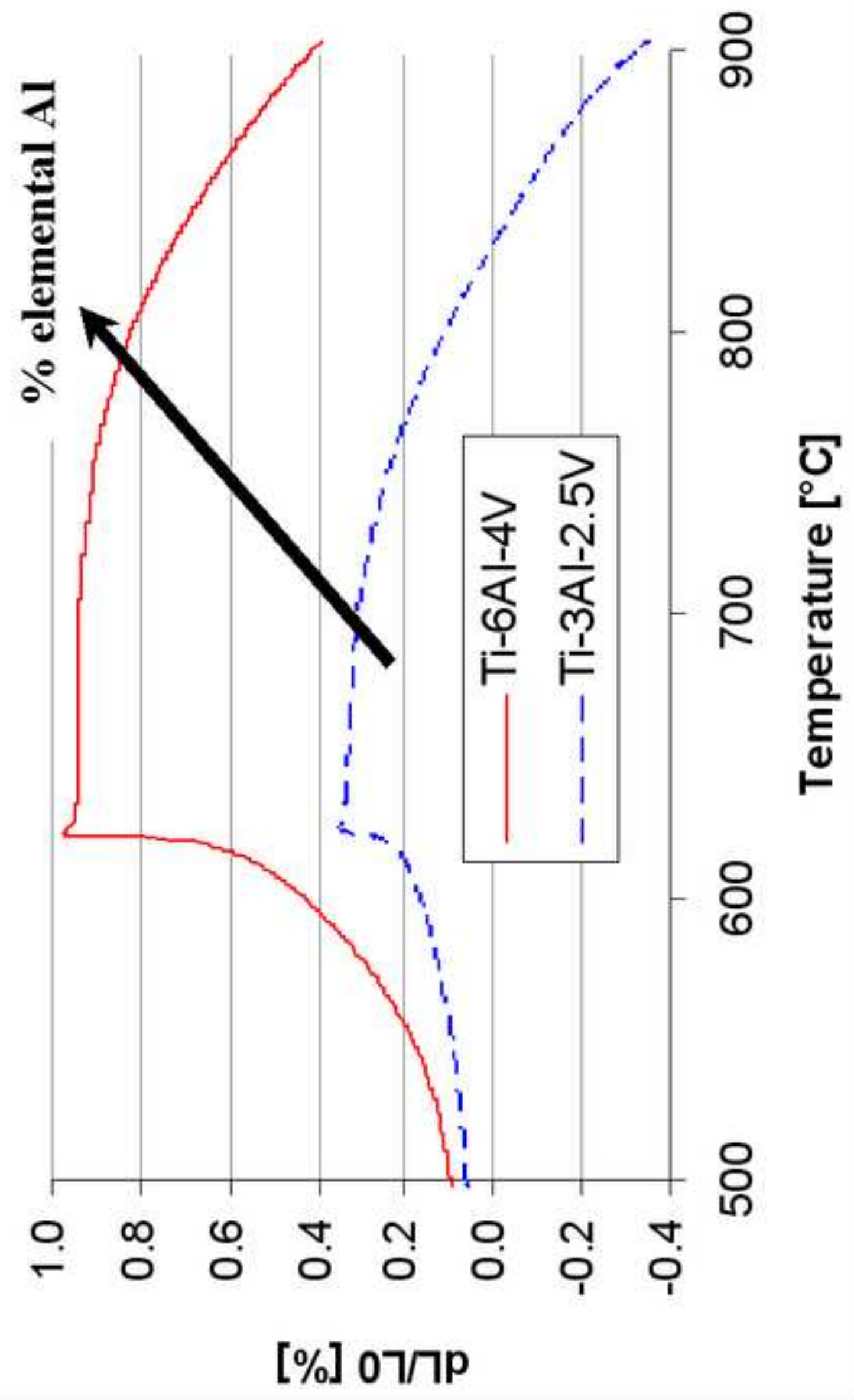




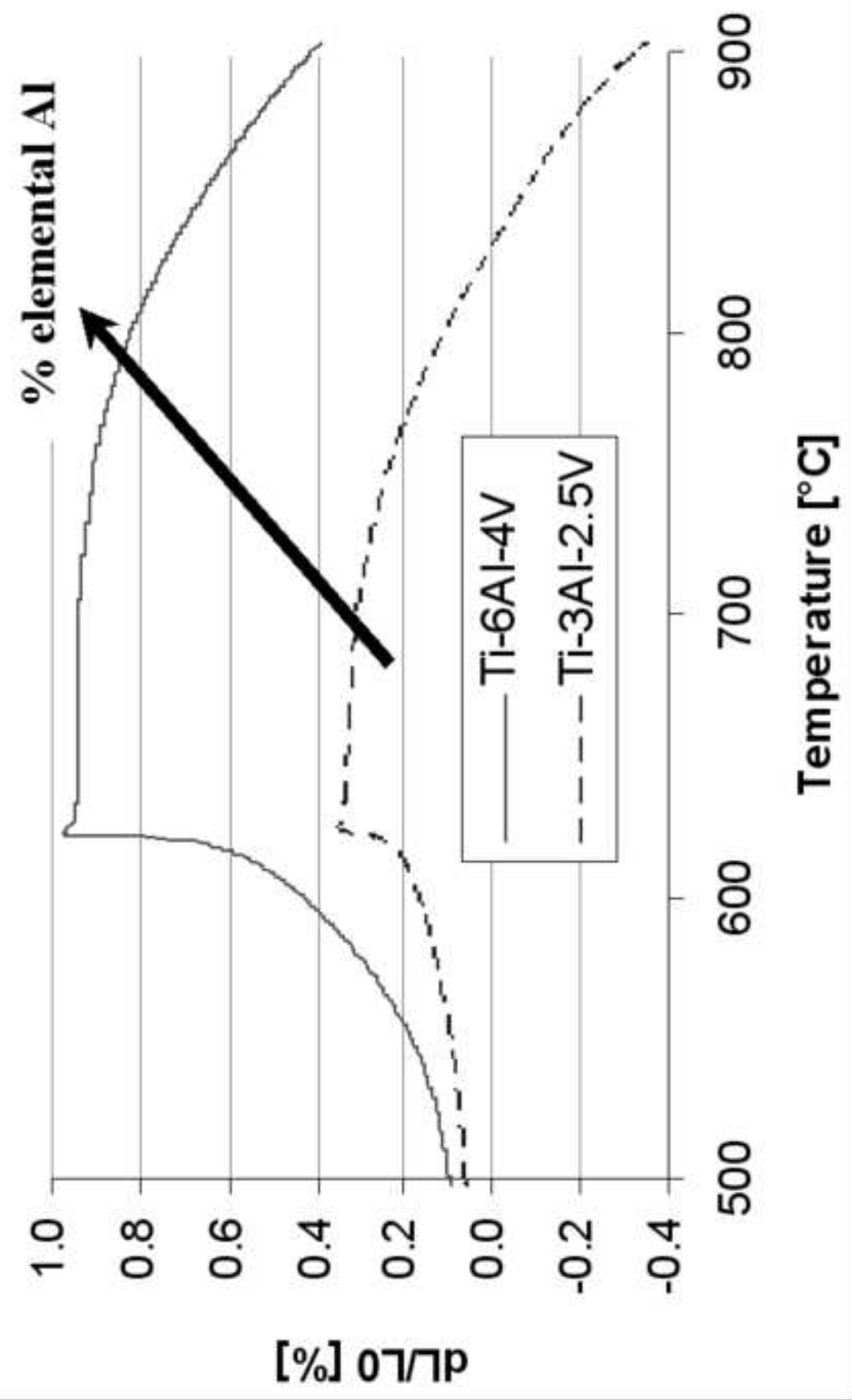




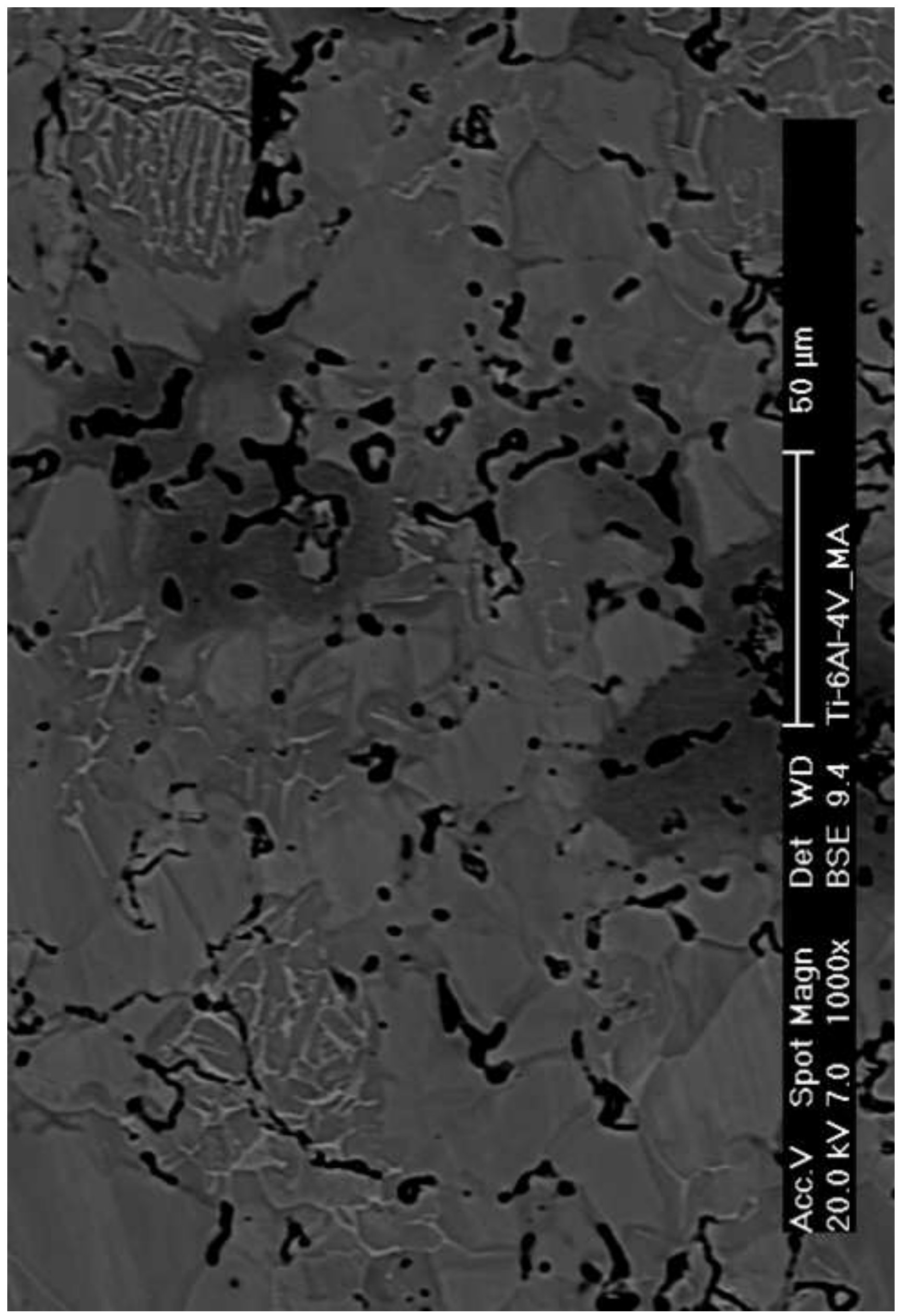




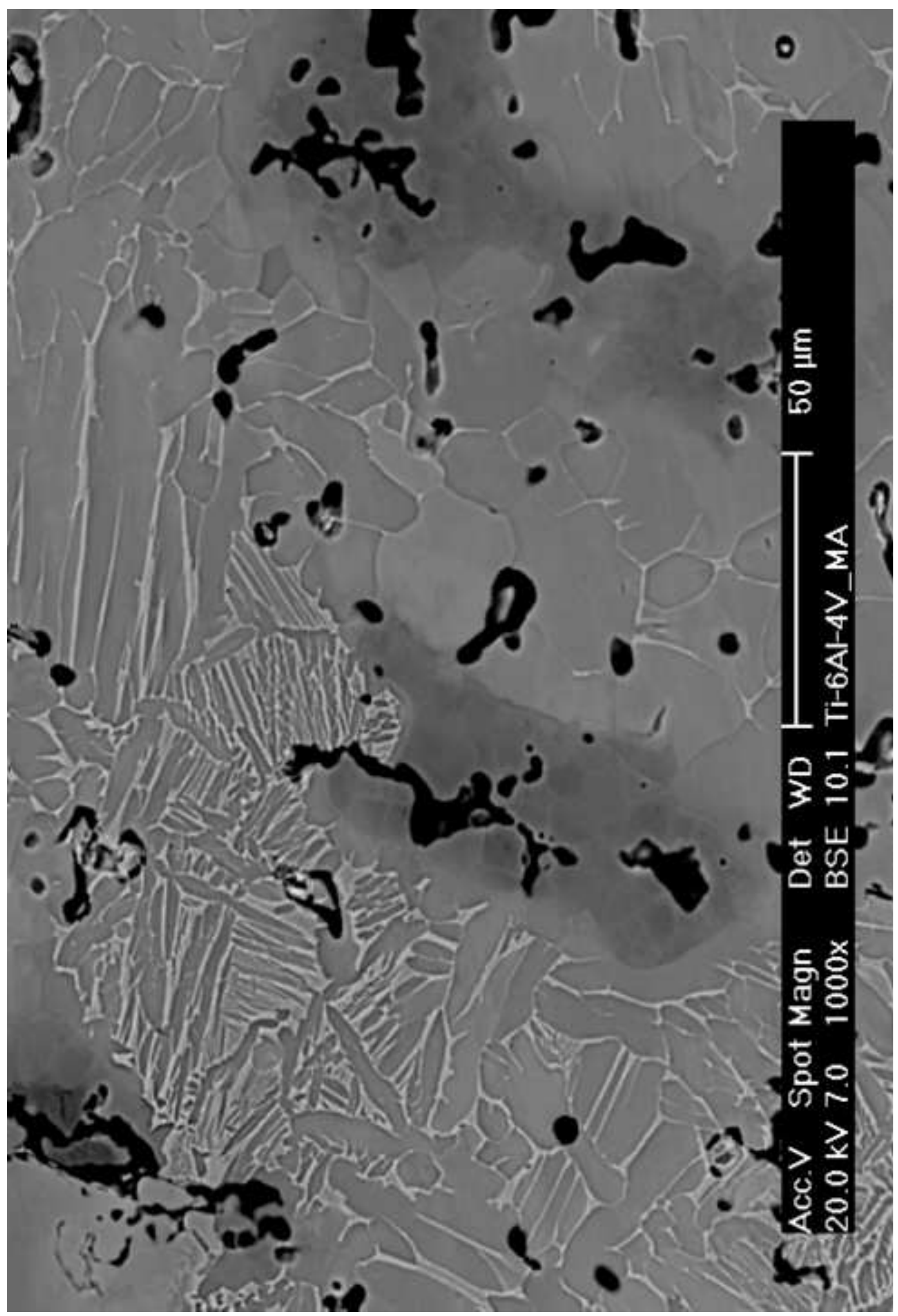




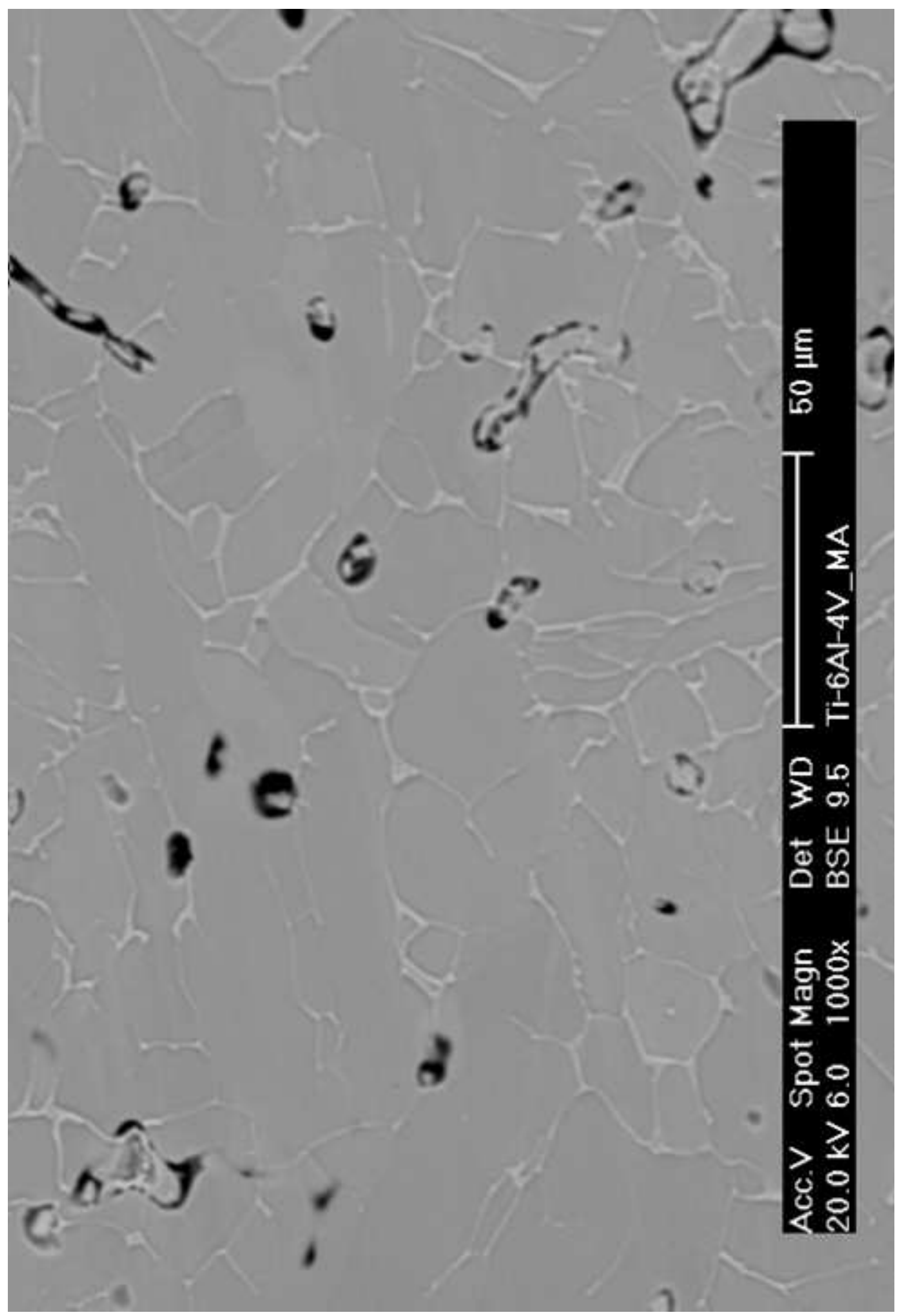




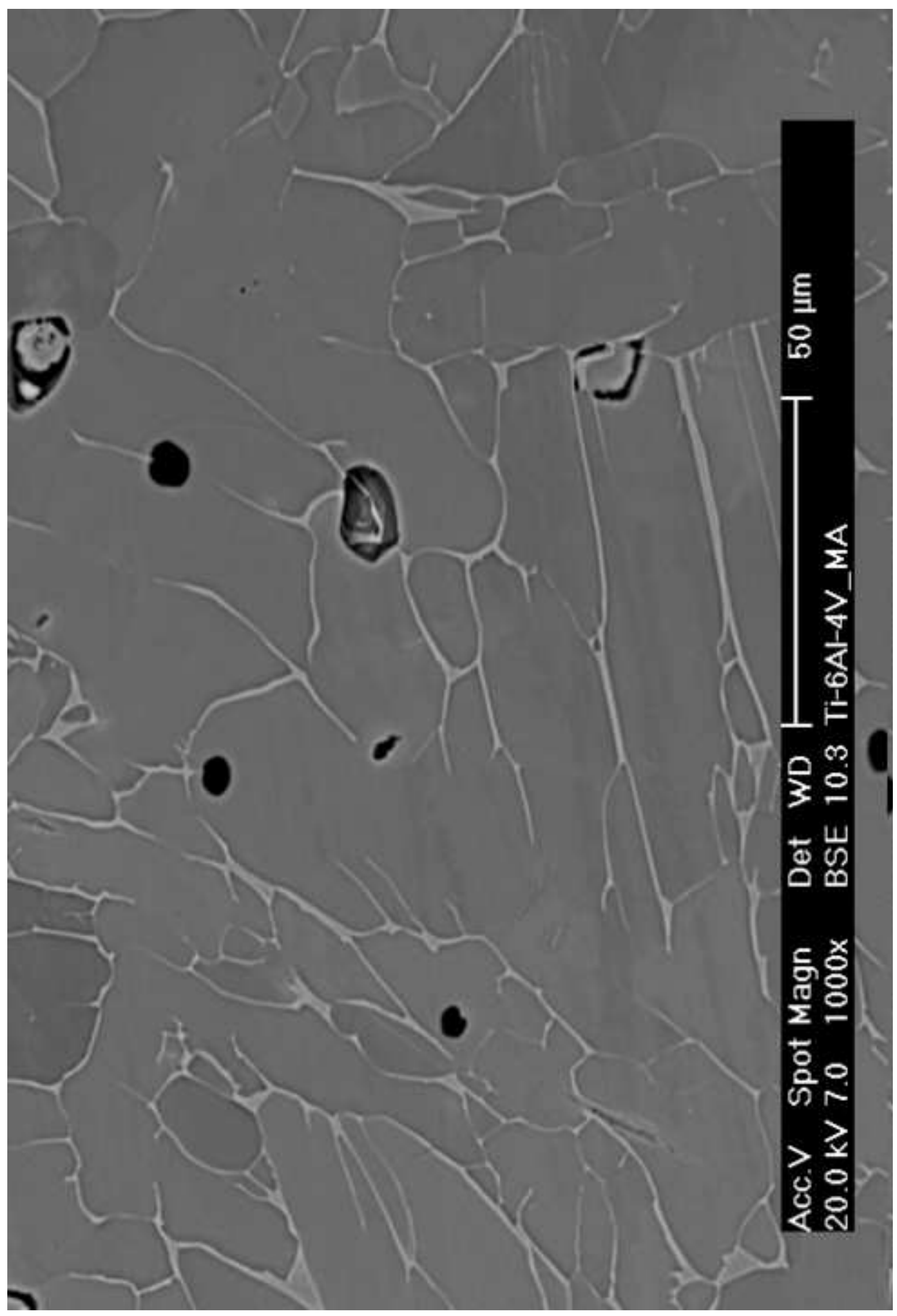




\section{息}
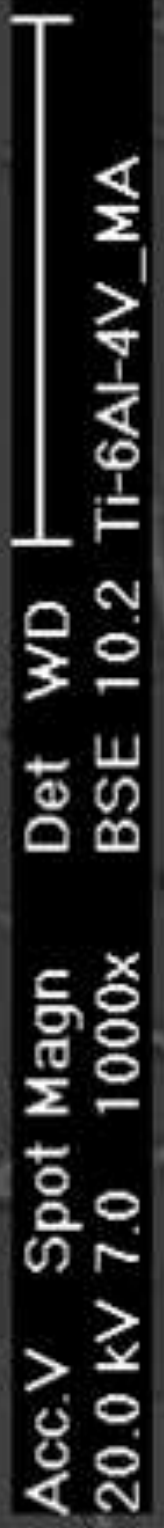


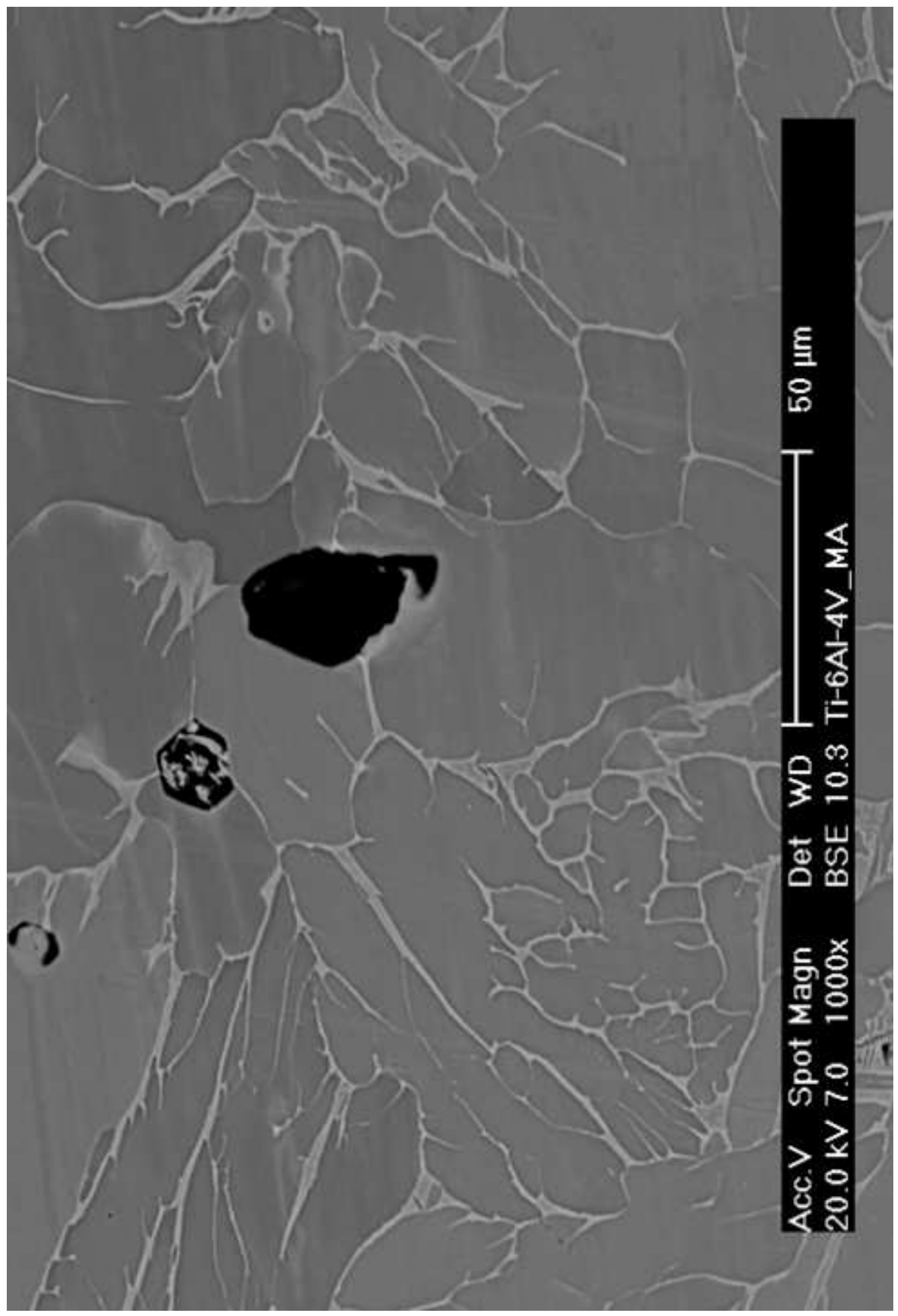




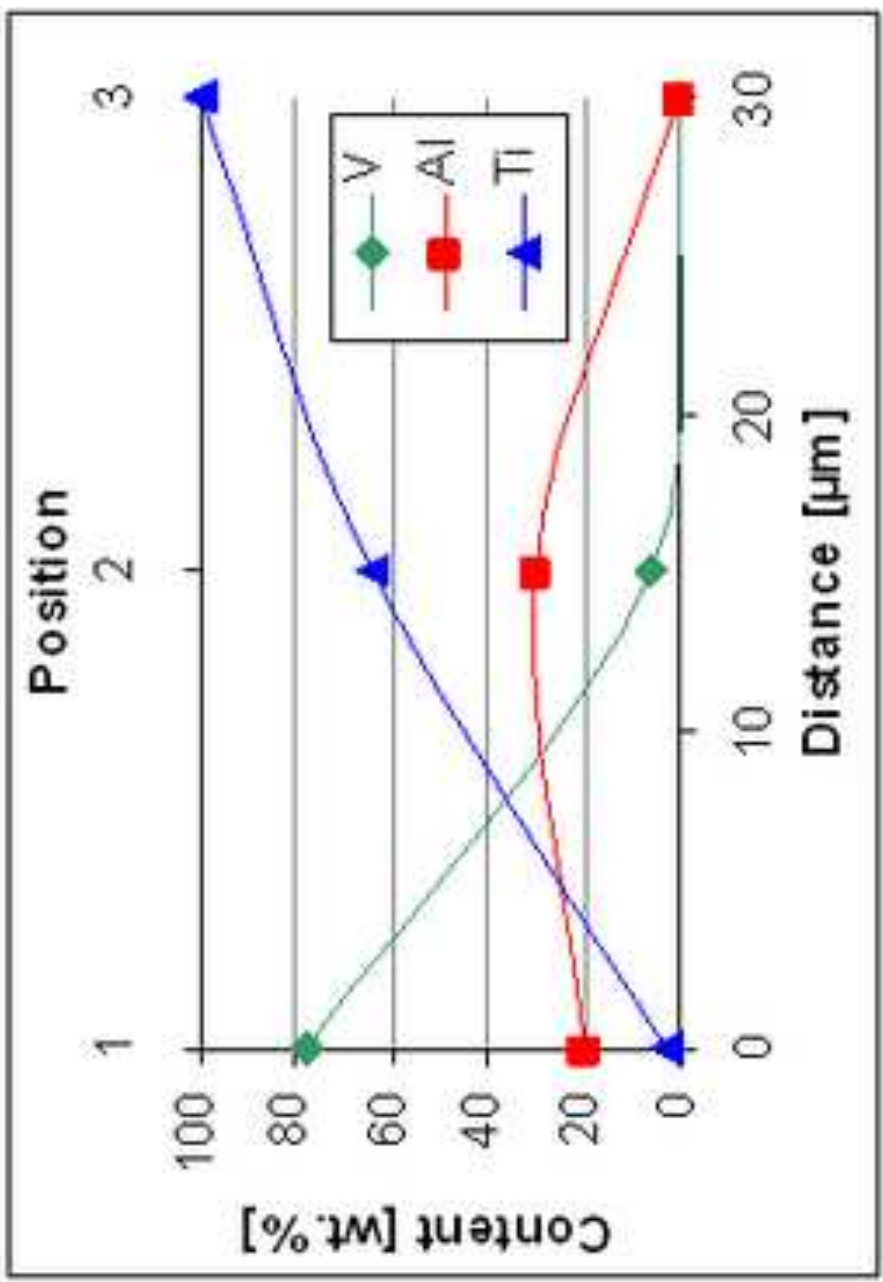

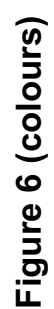

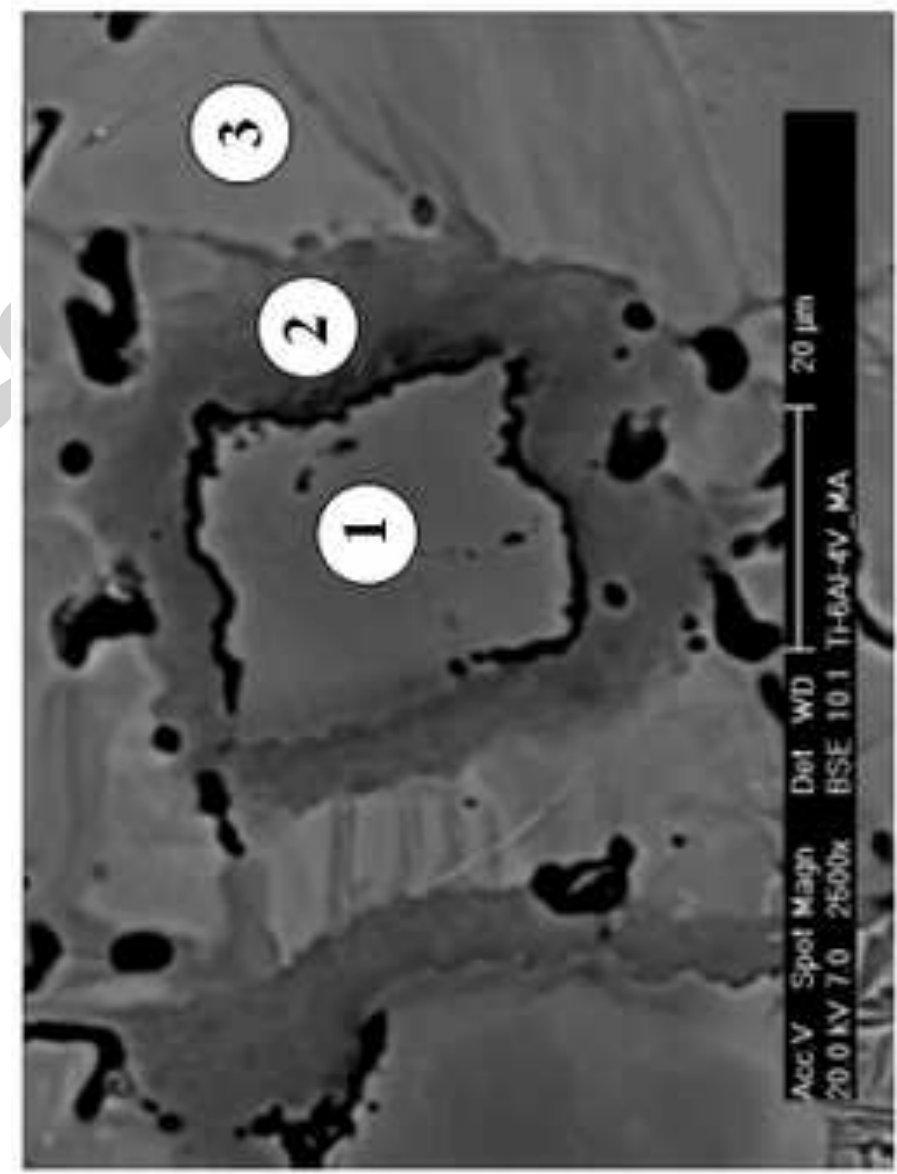



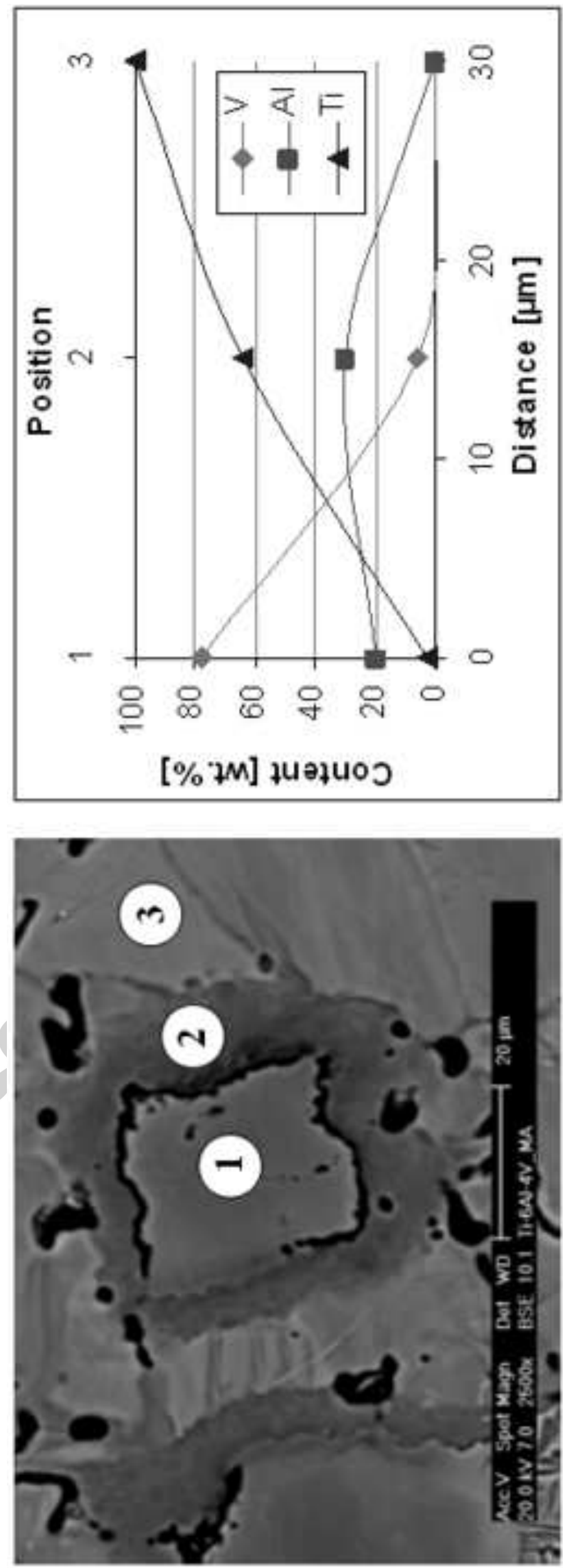


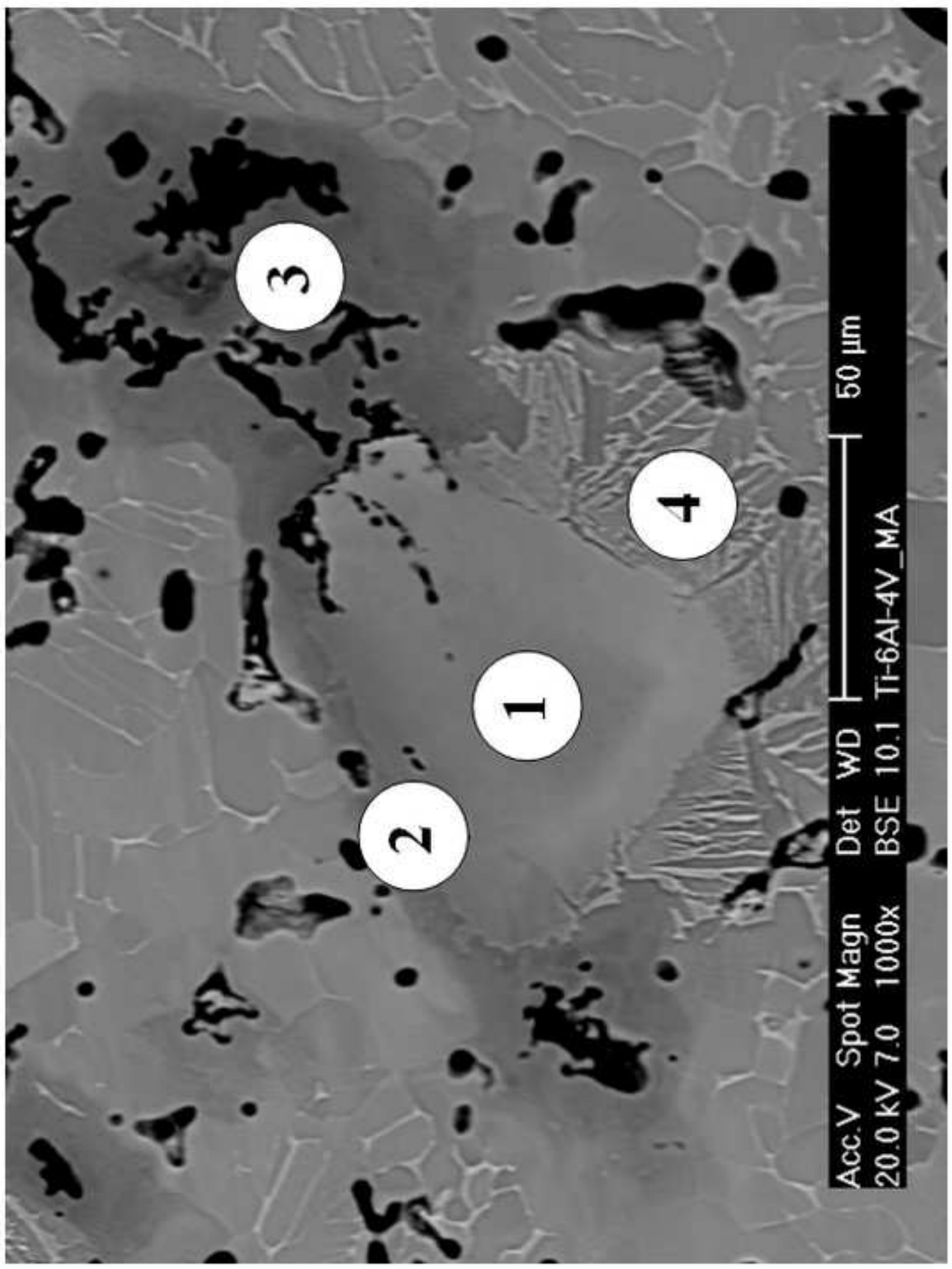




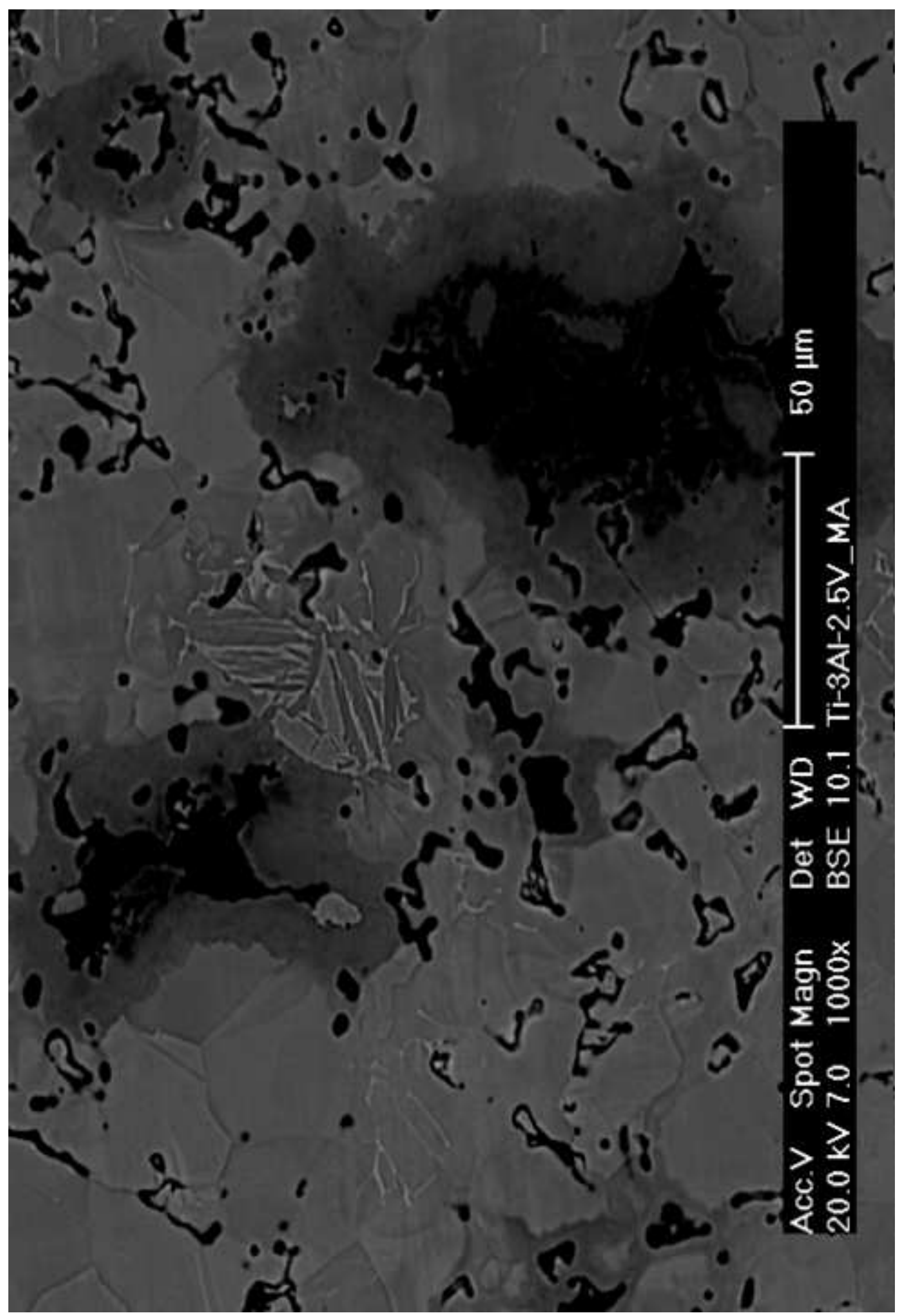




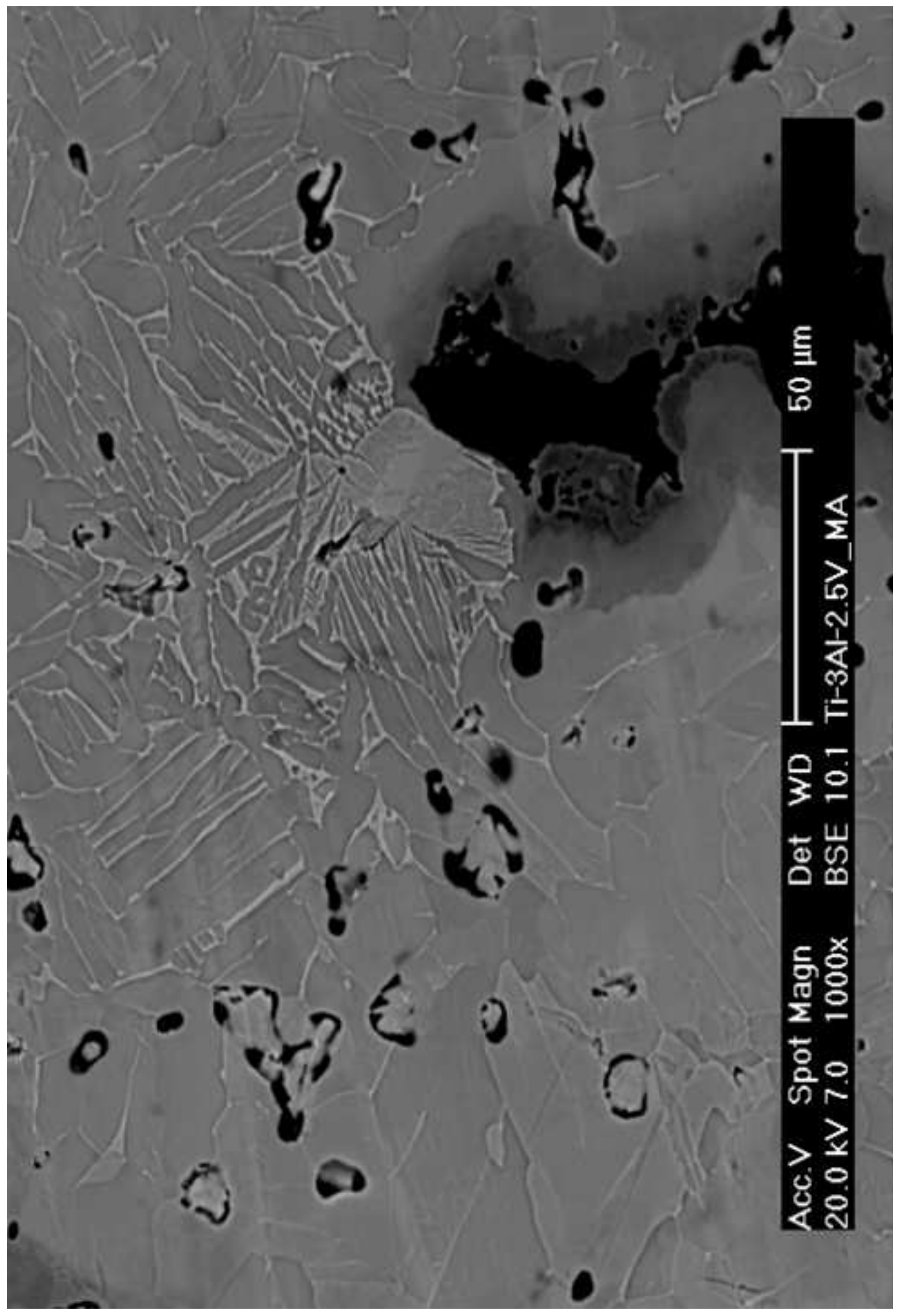




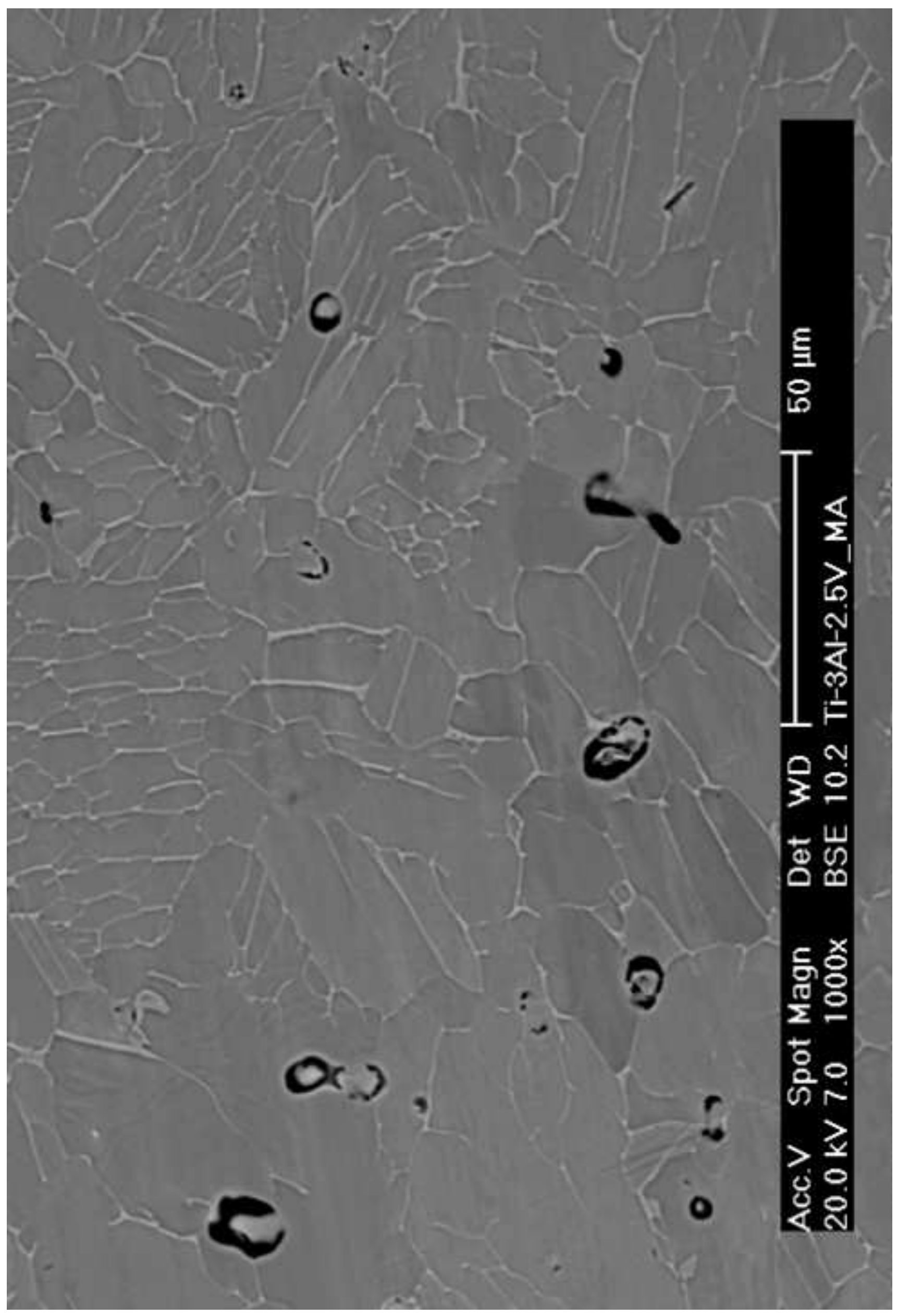




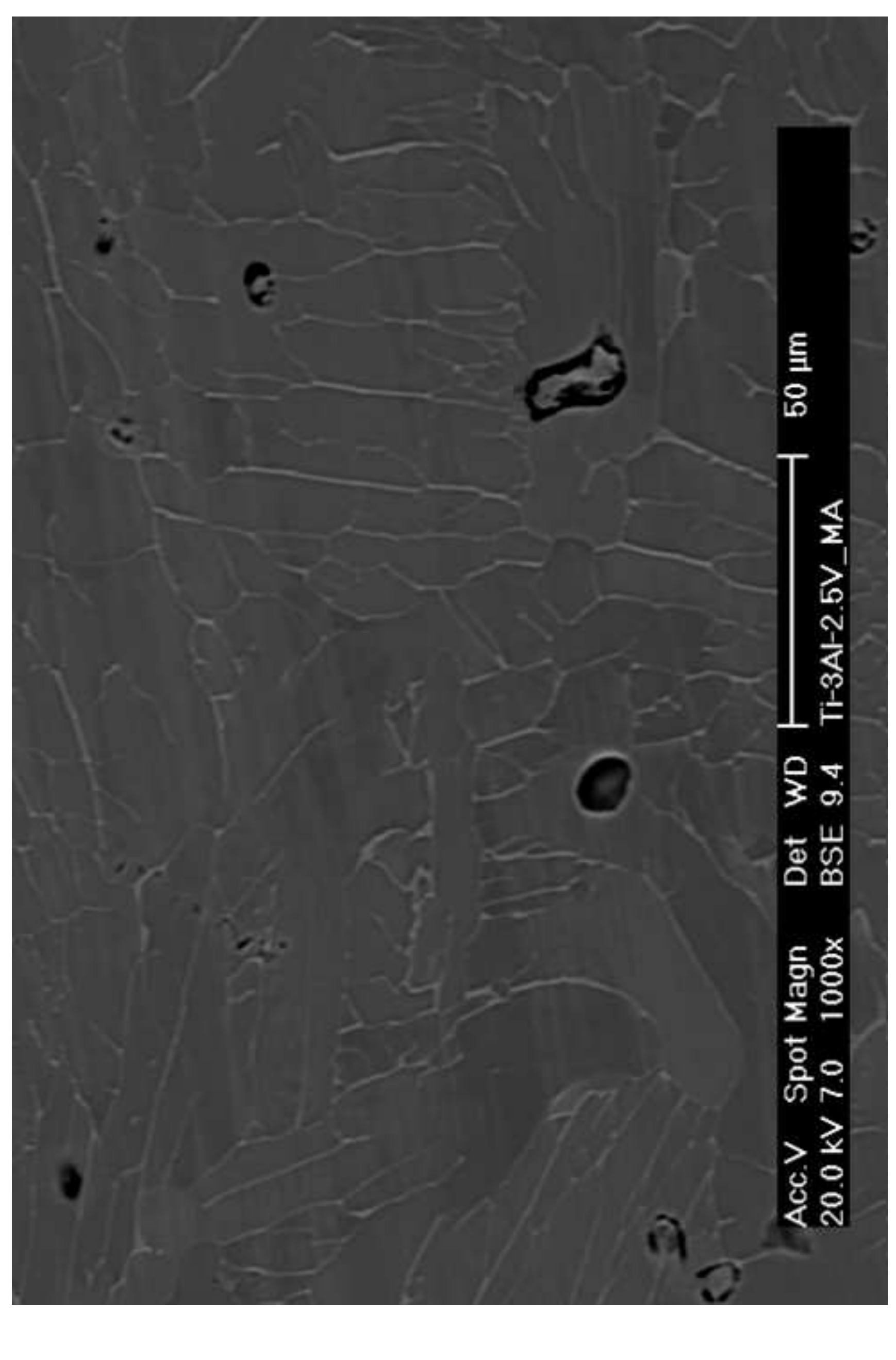




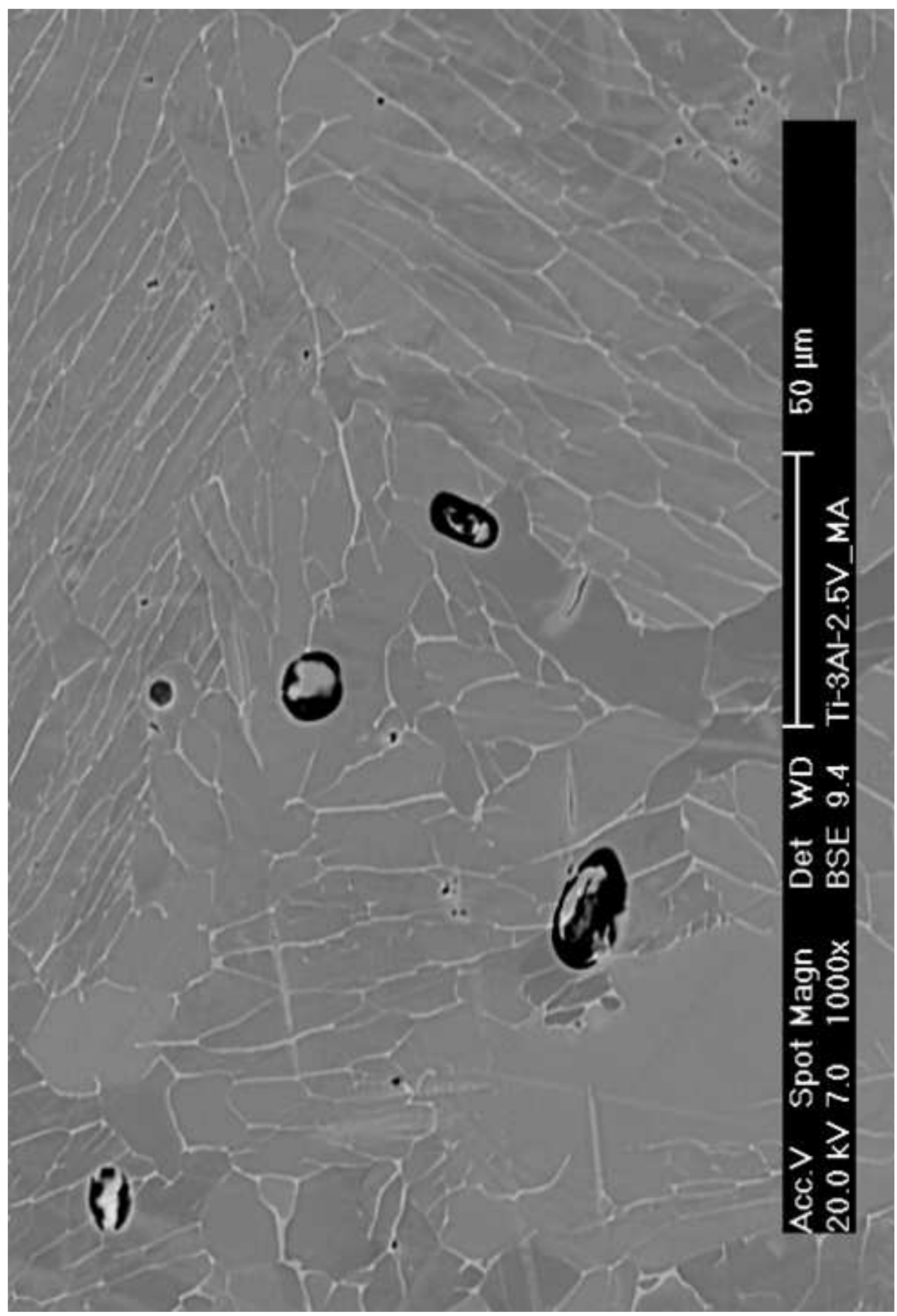




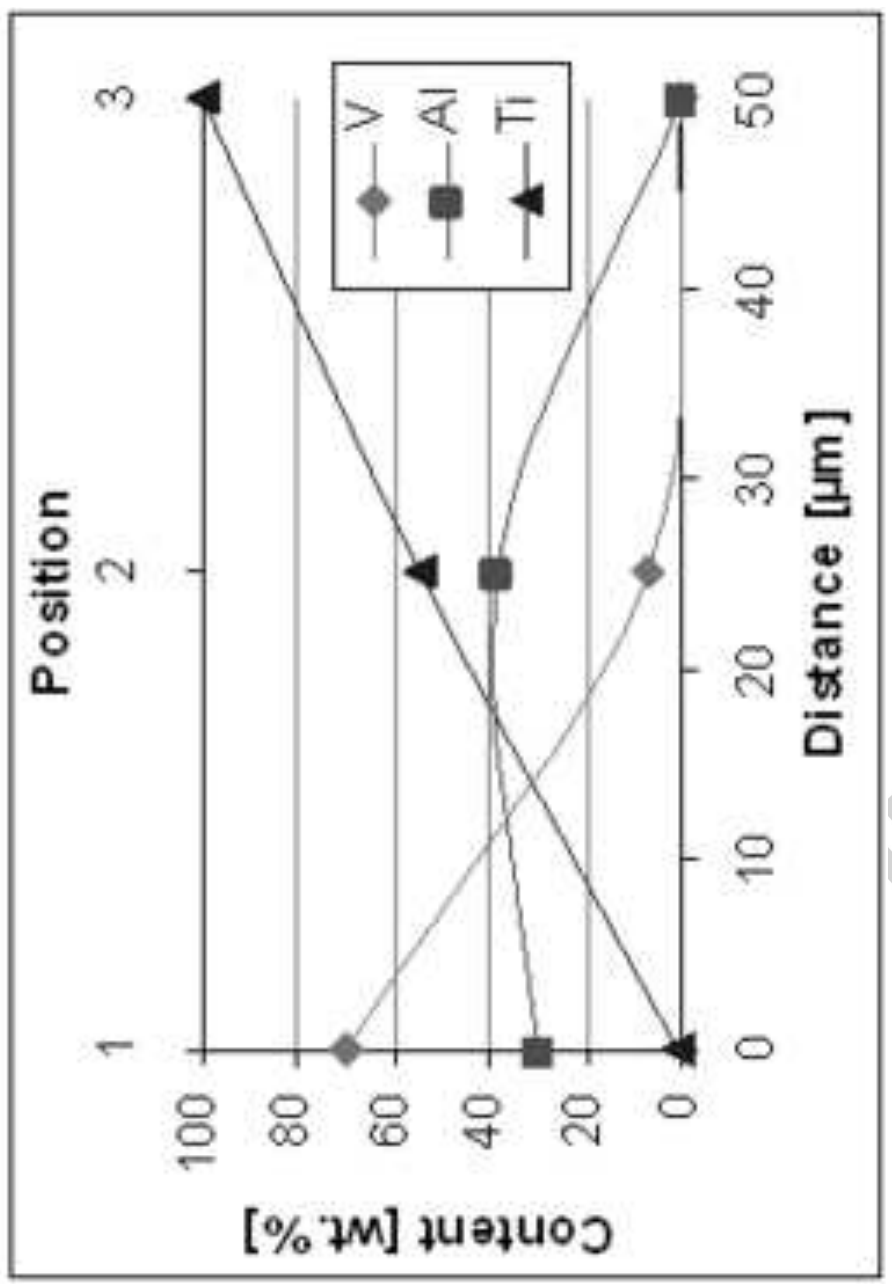

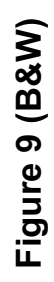

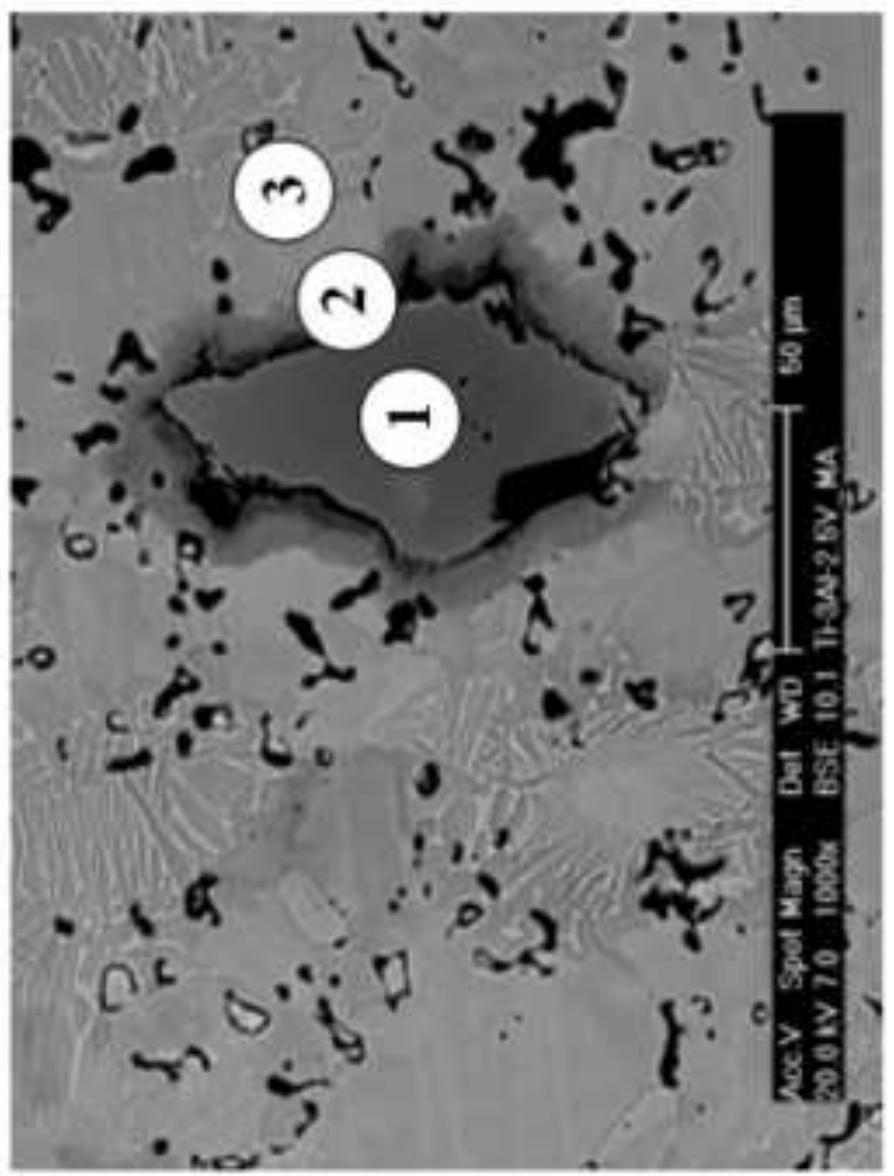




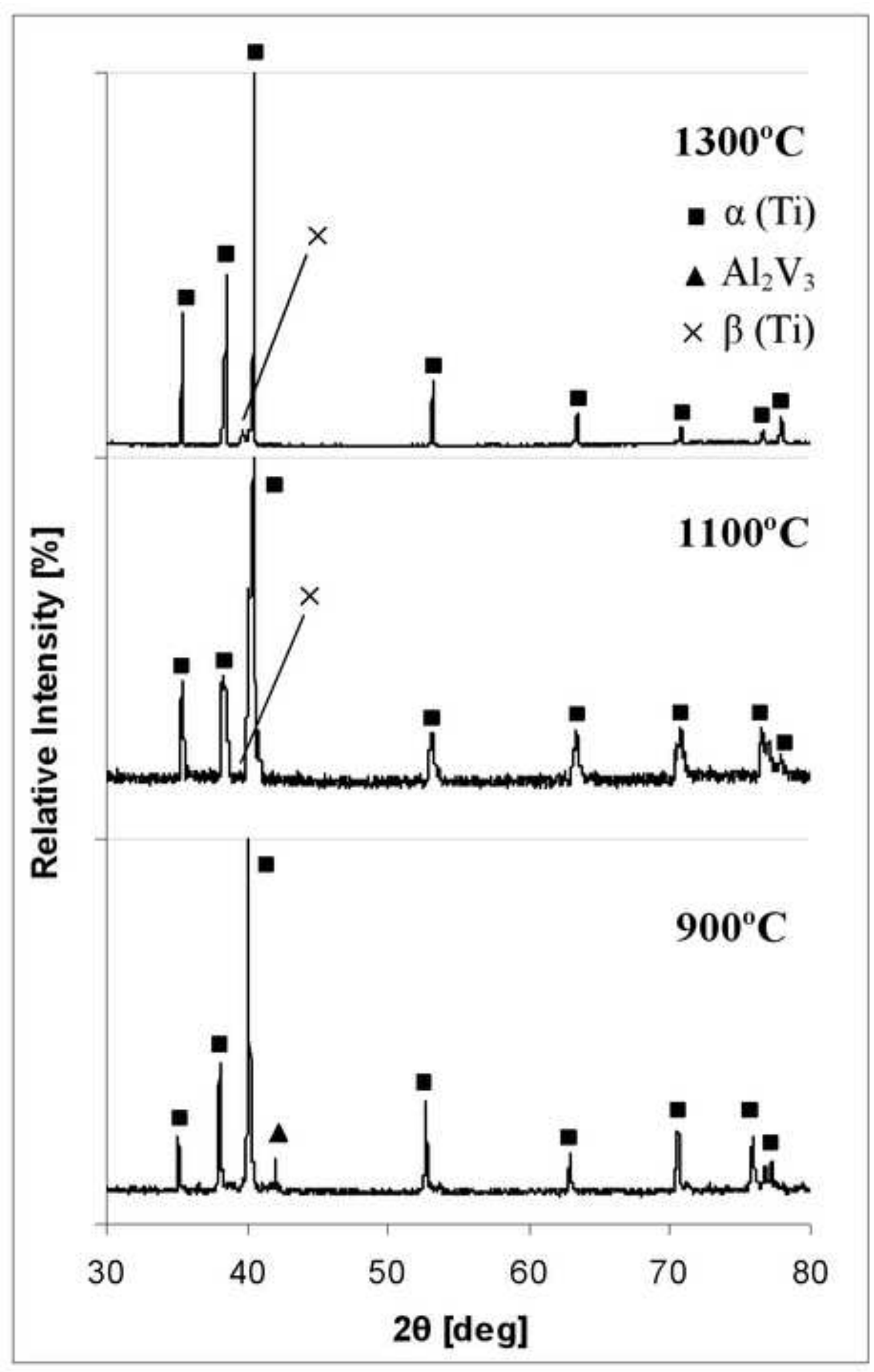

Figure 10 a)
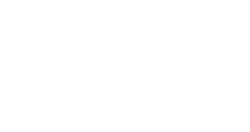
Figure $10 \mathrm{~b}$ )
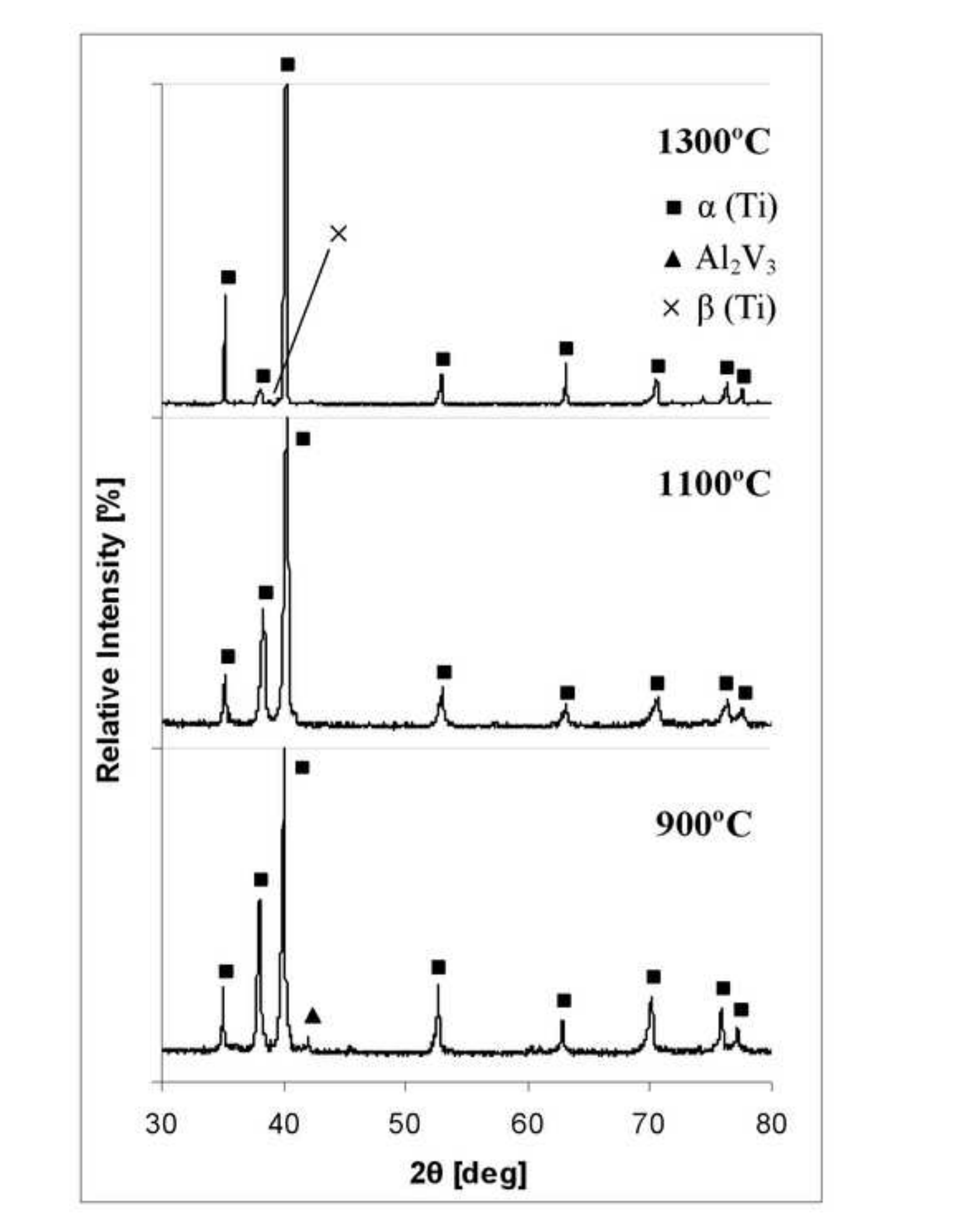


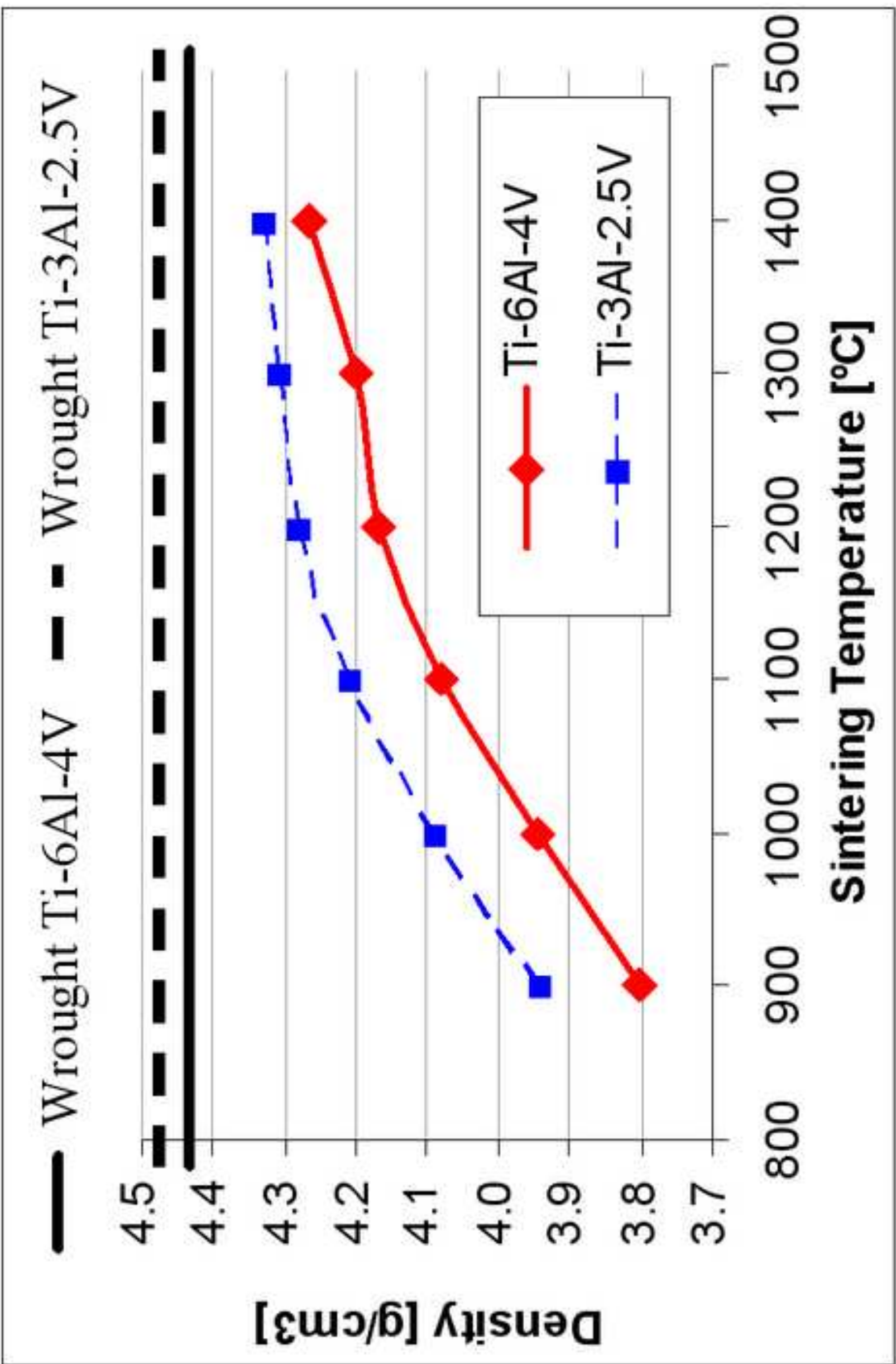




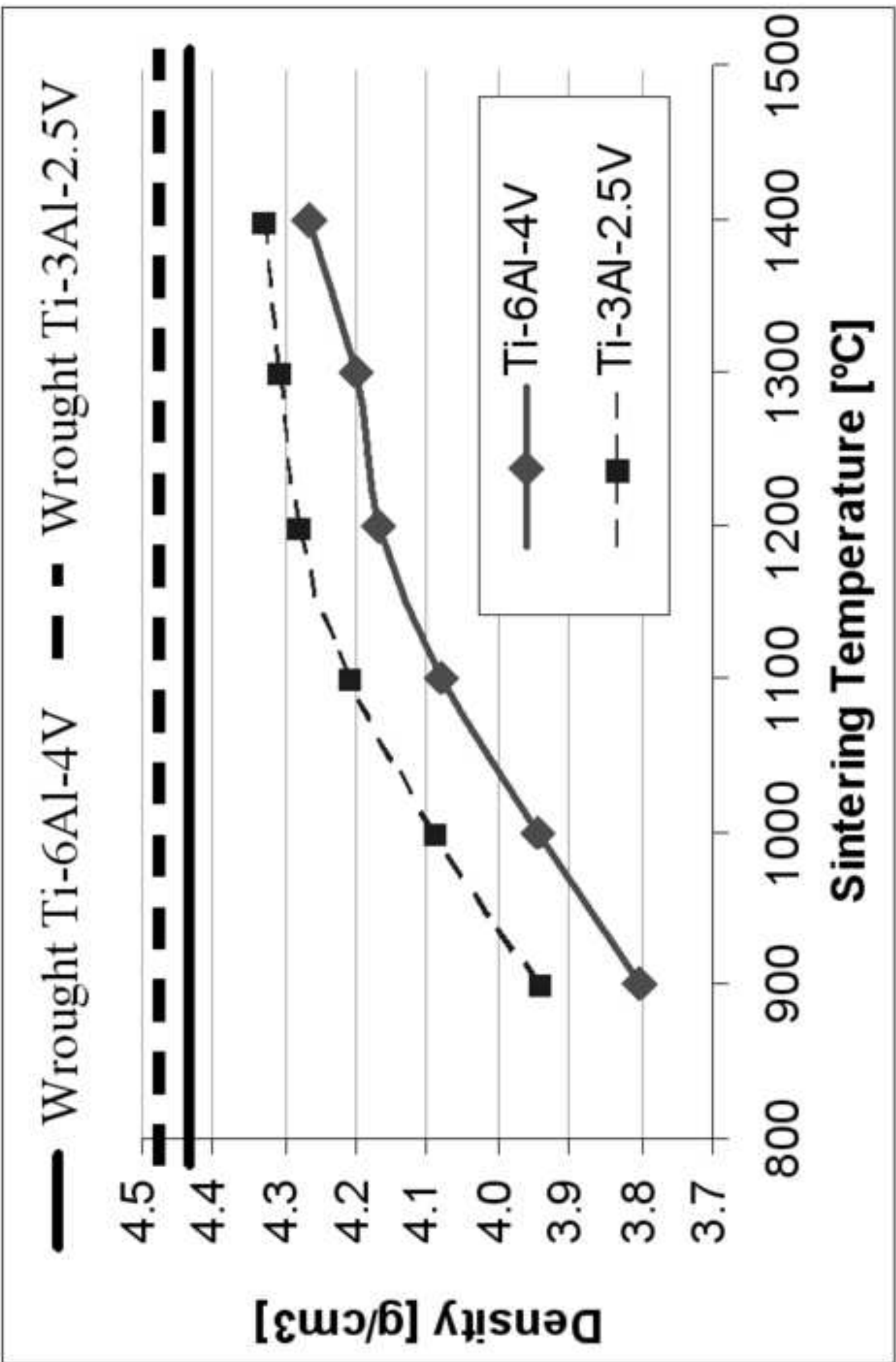



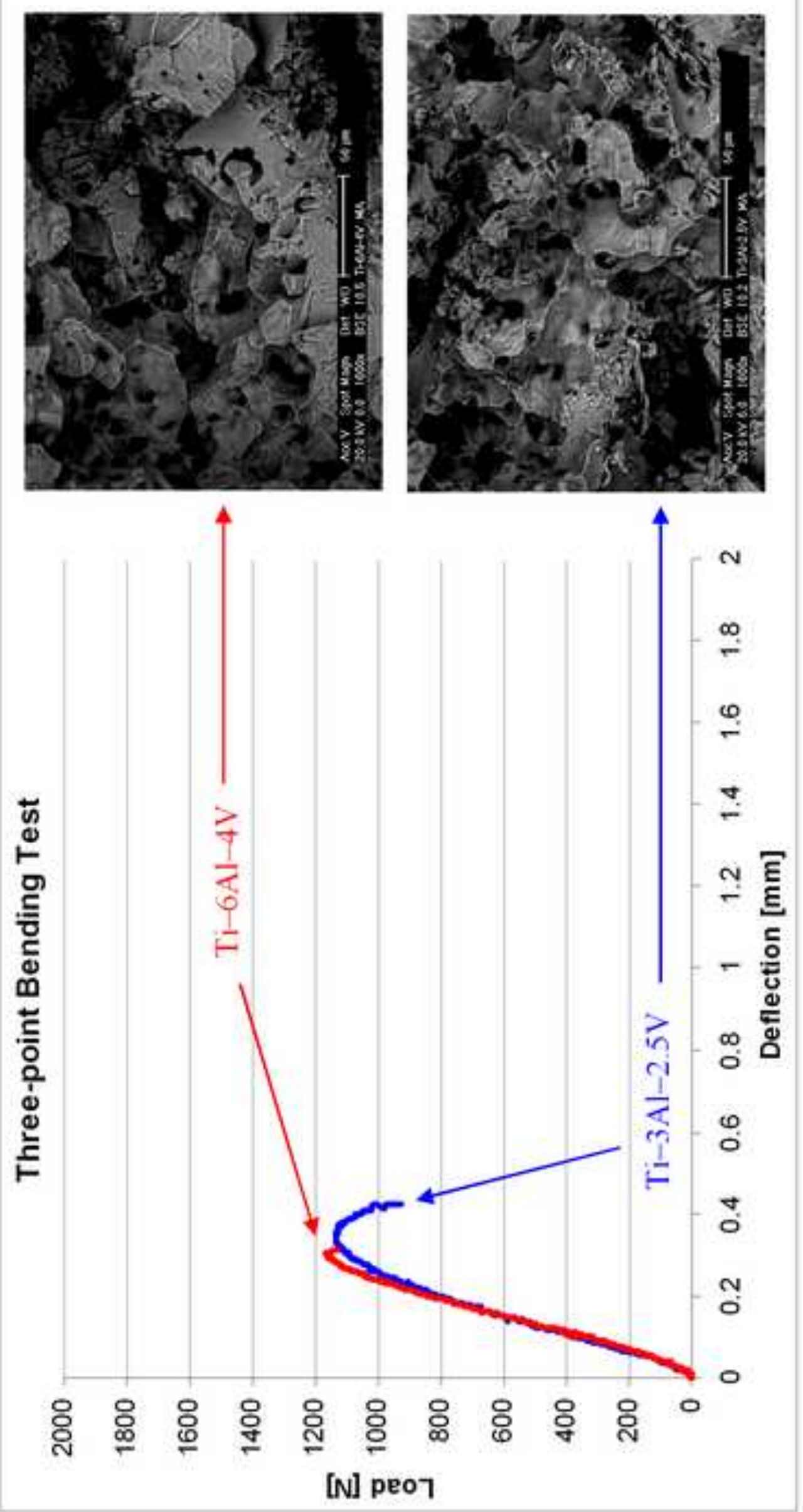


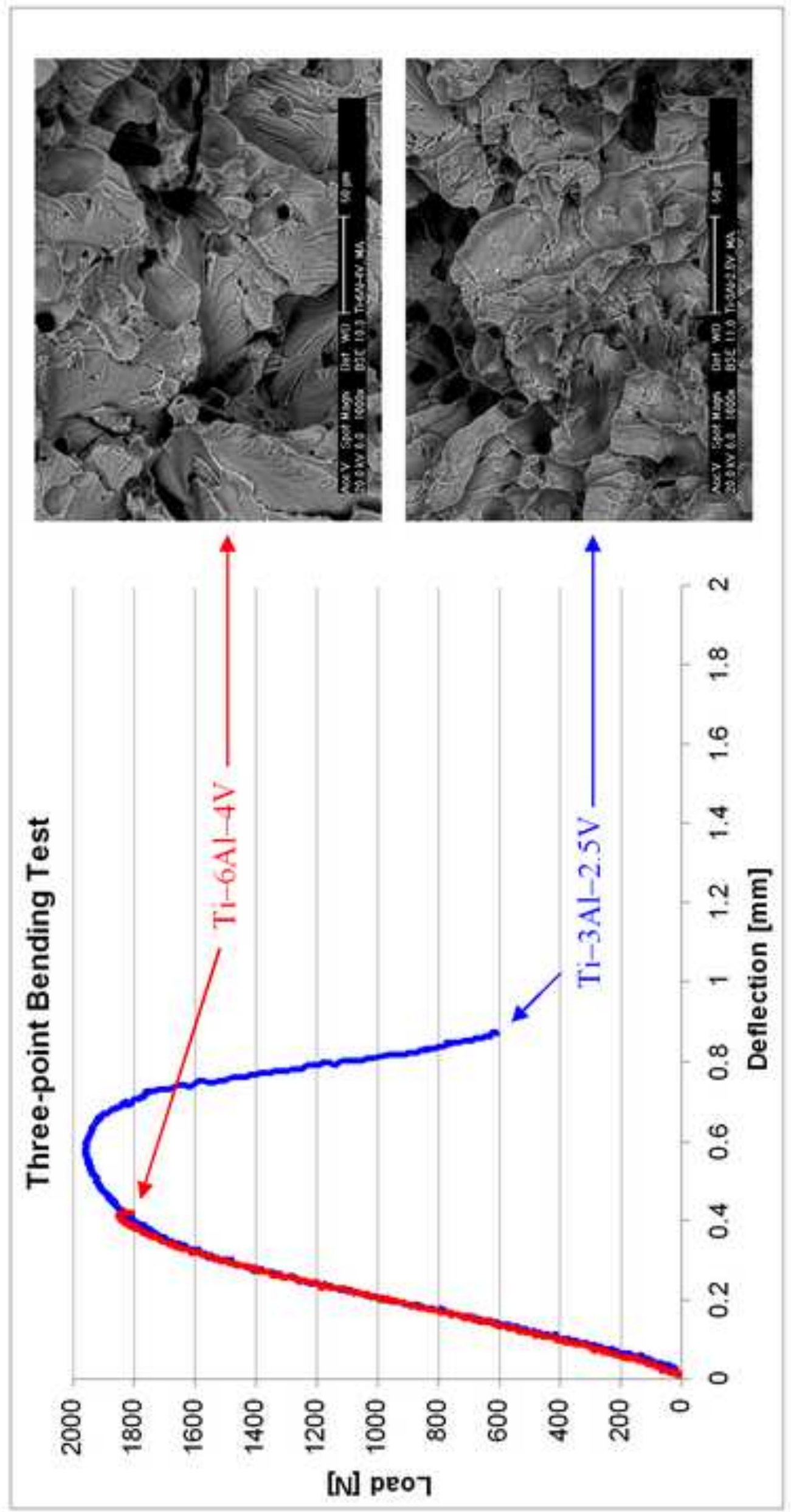




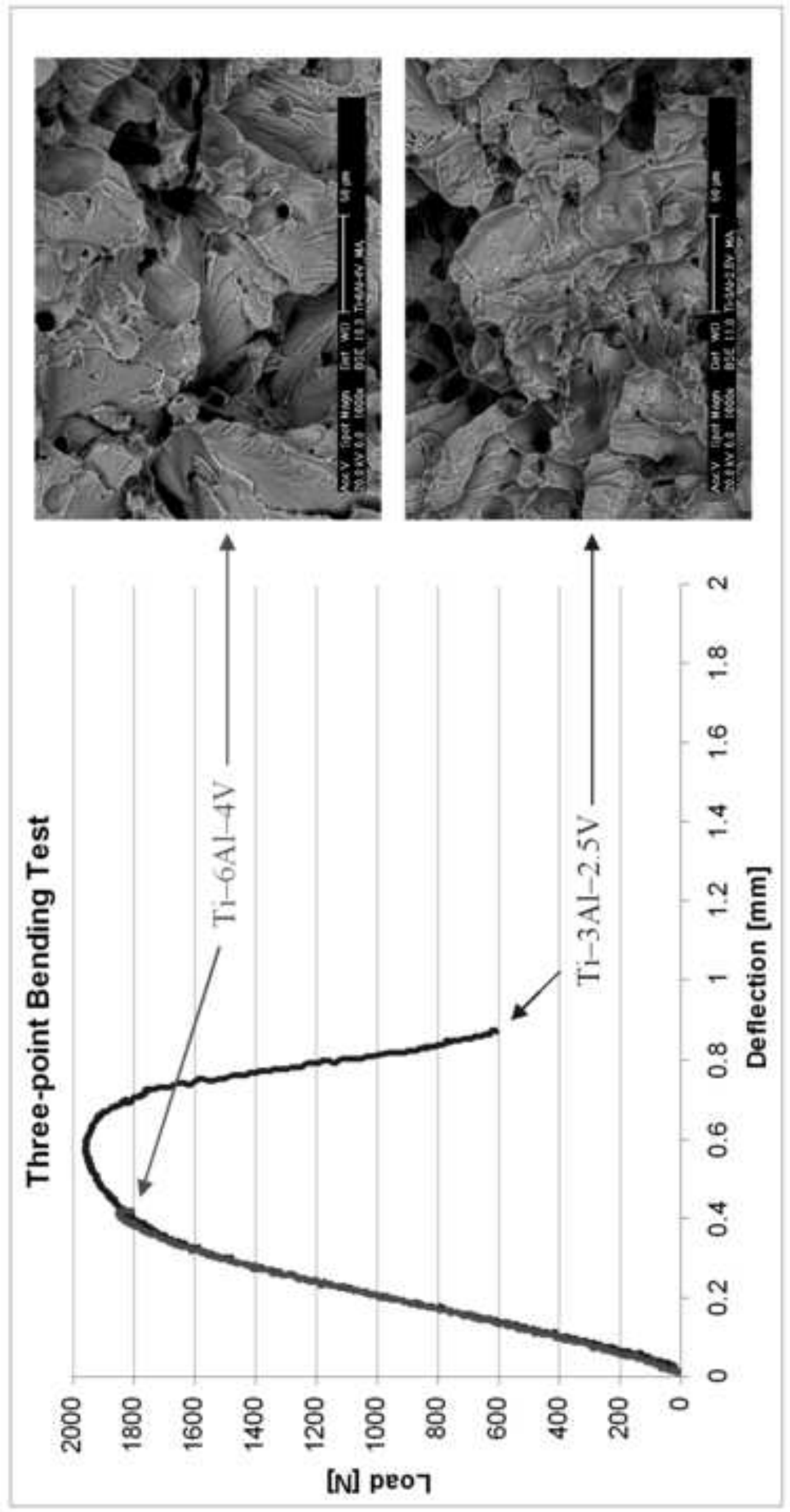




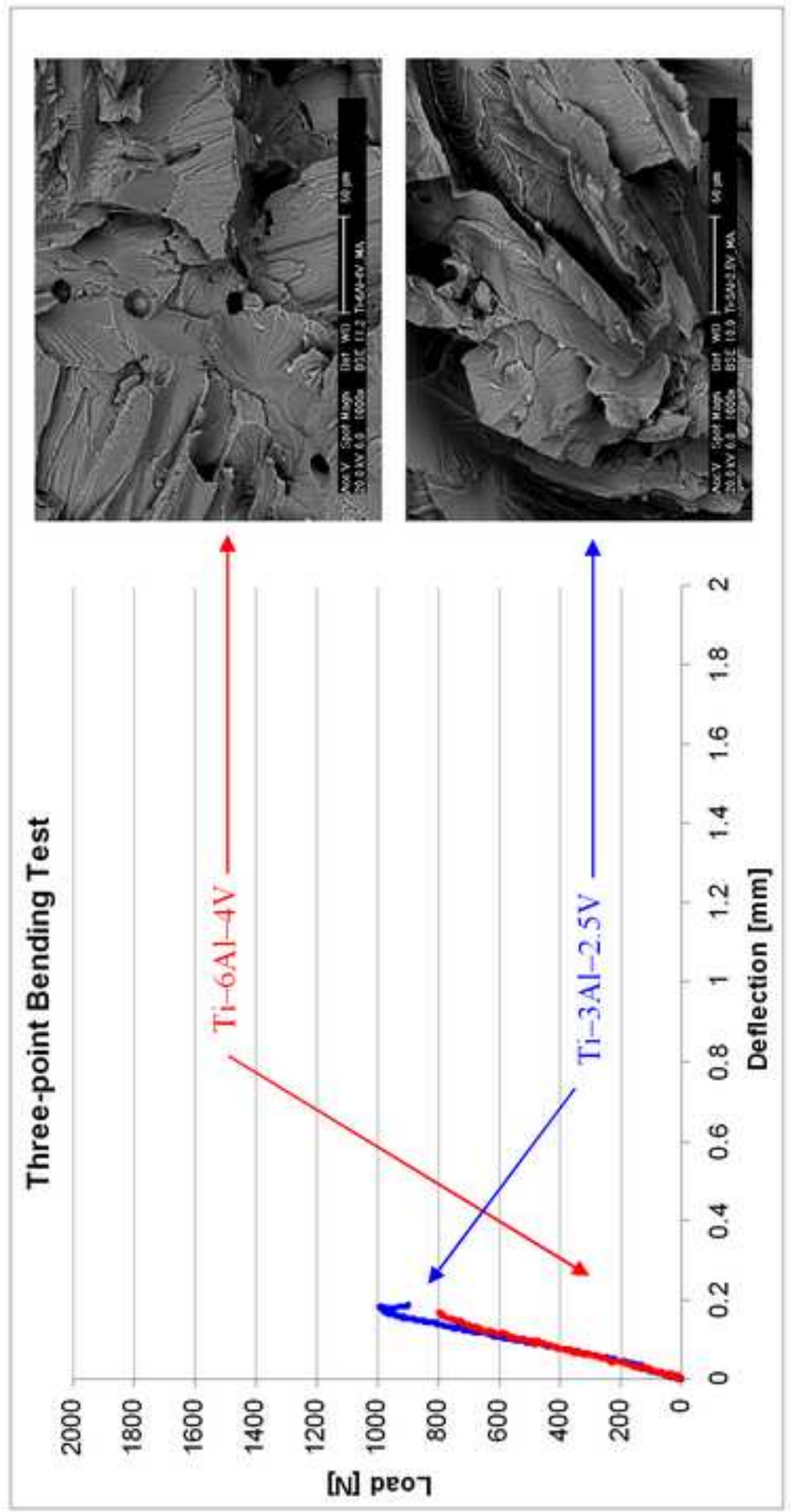




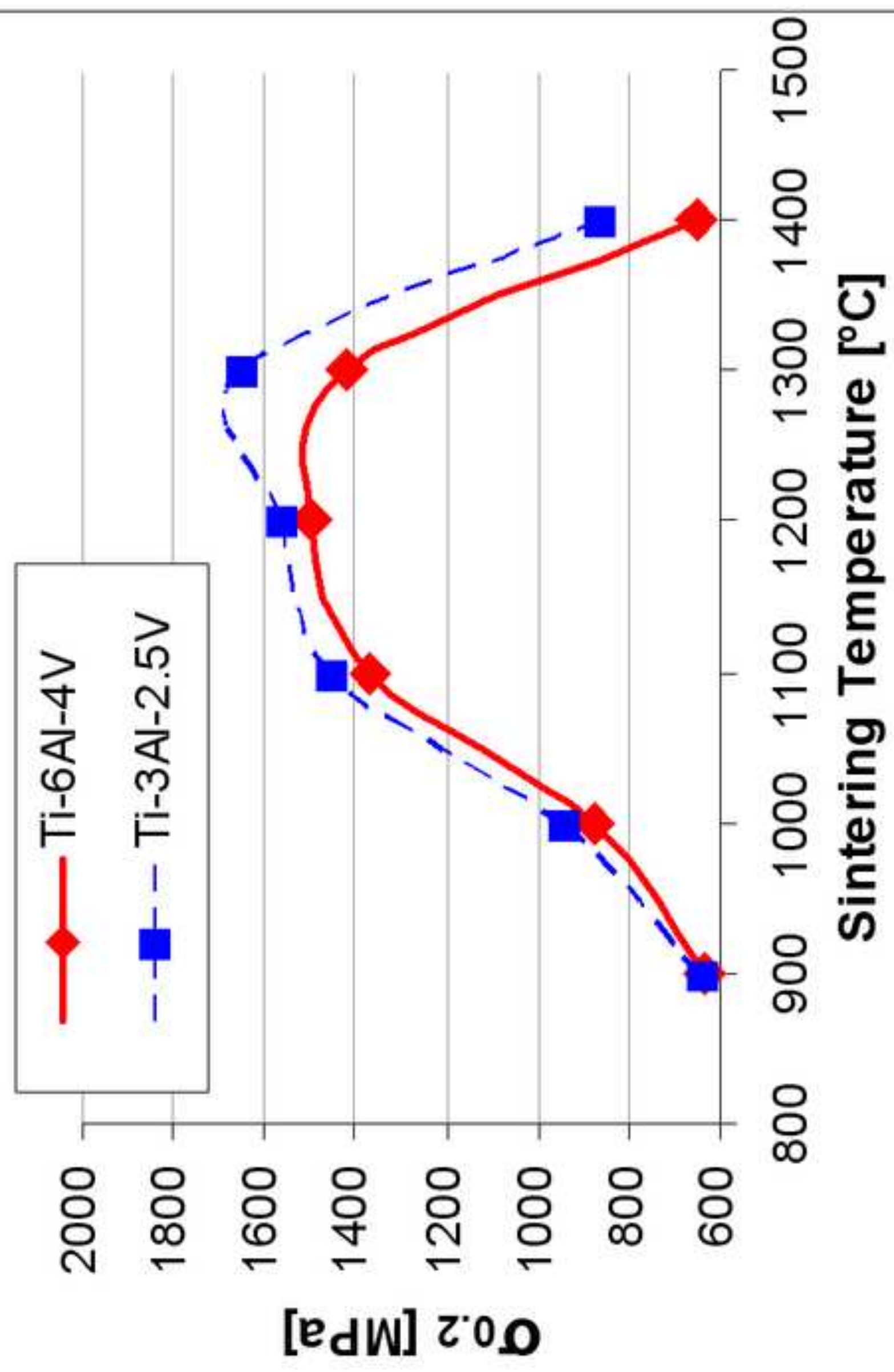




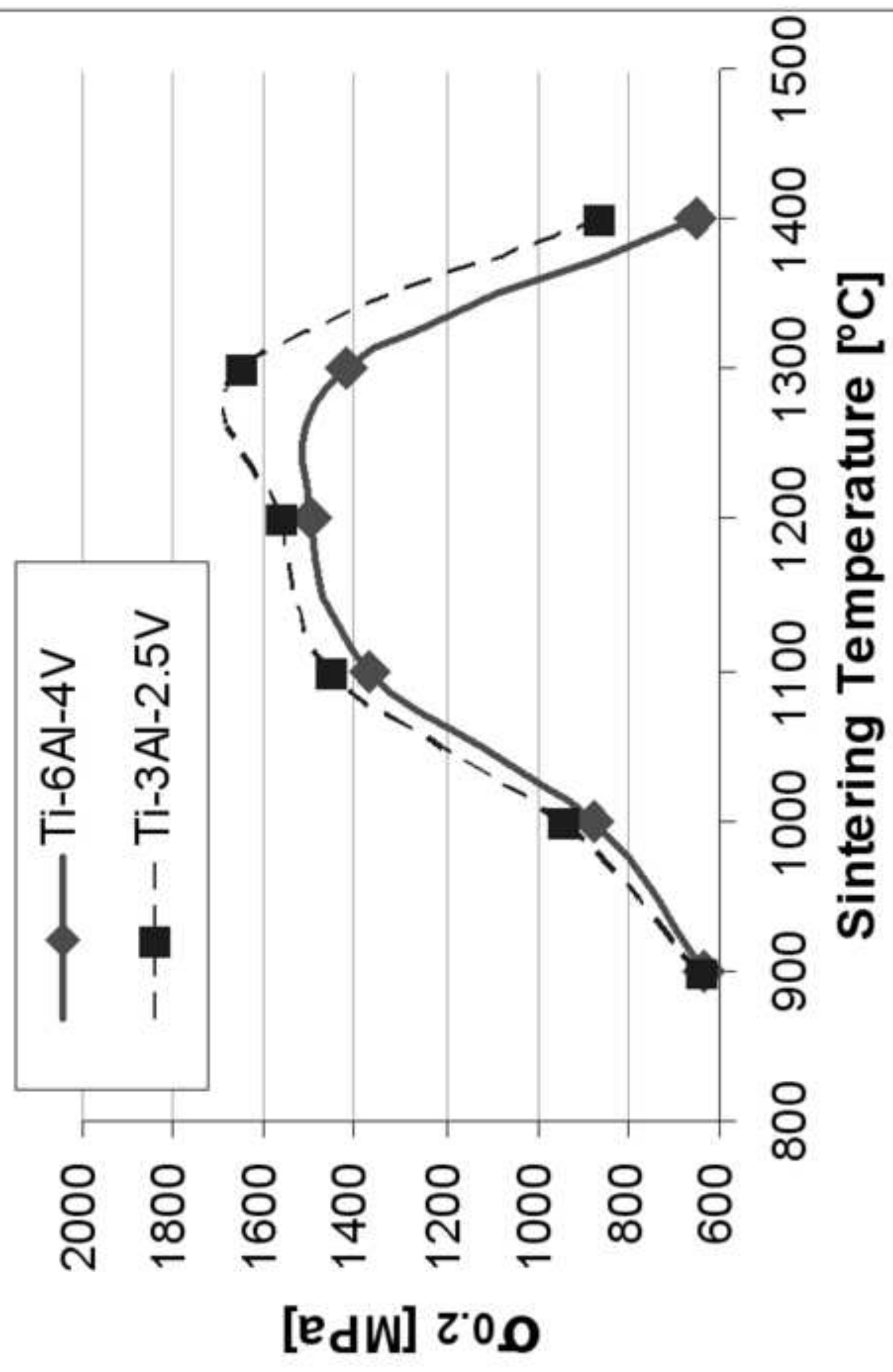




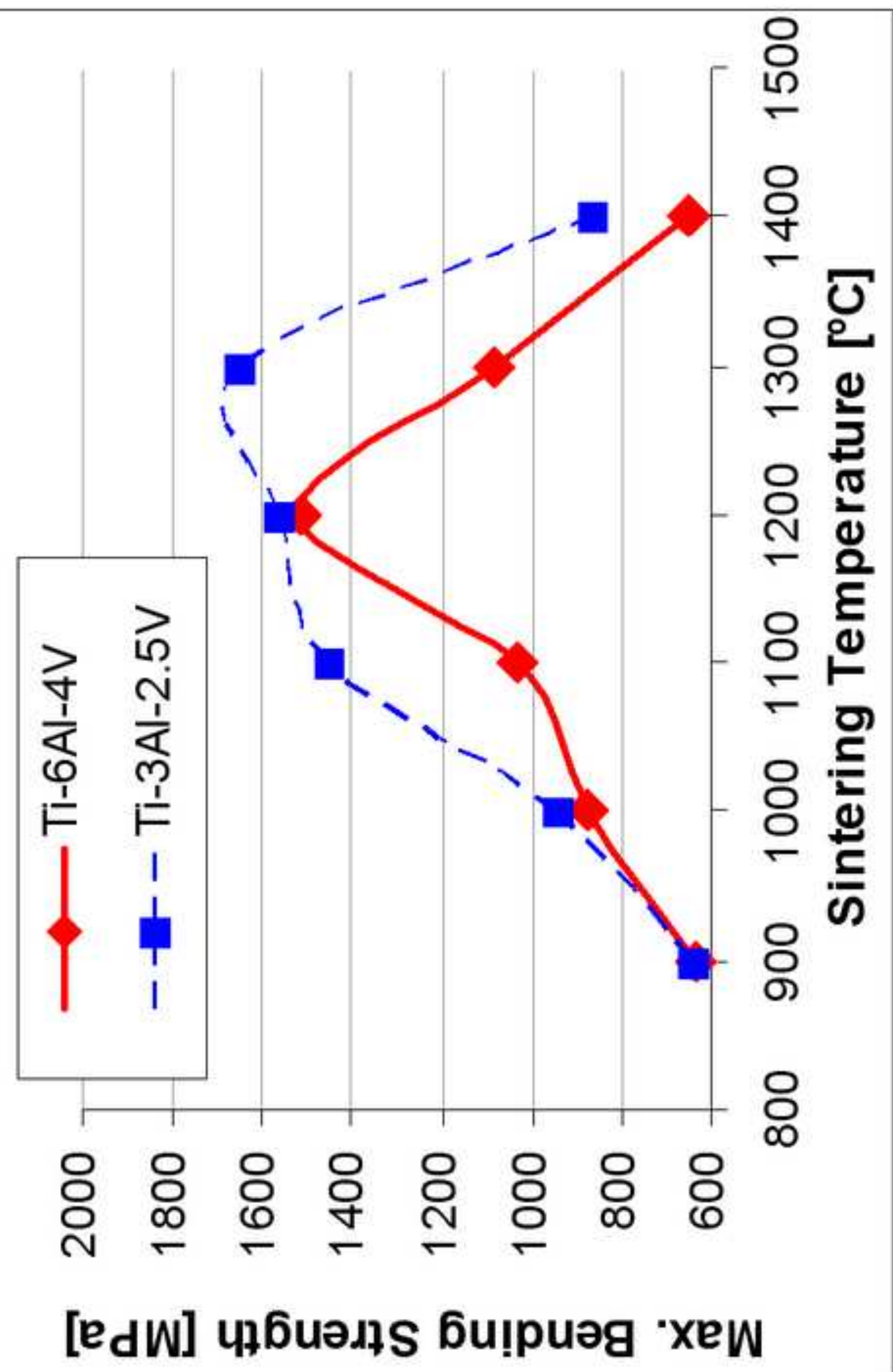




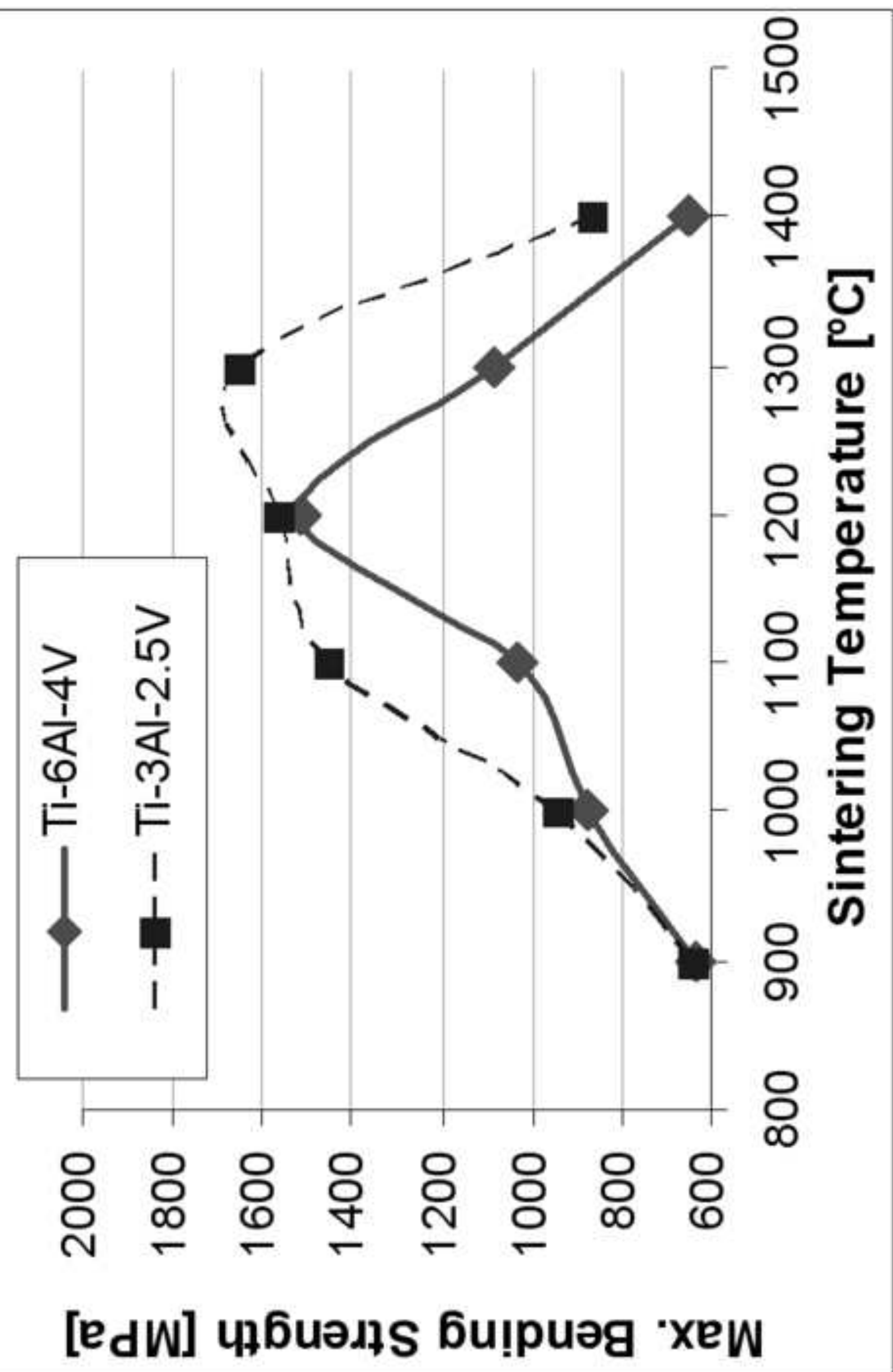




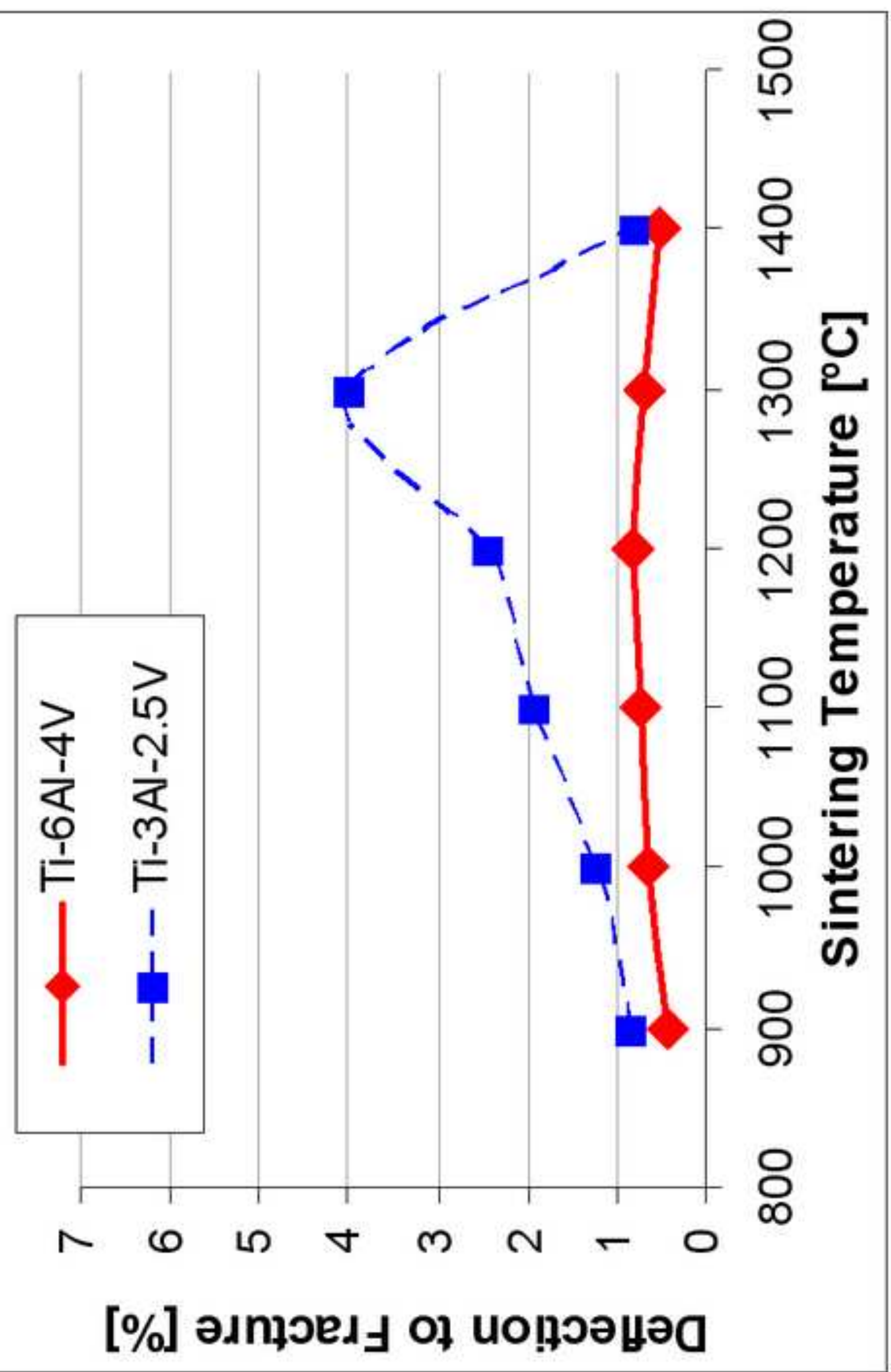




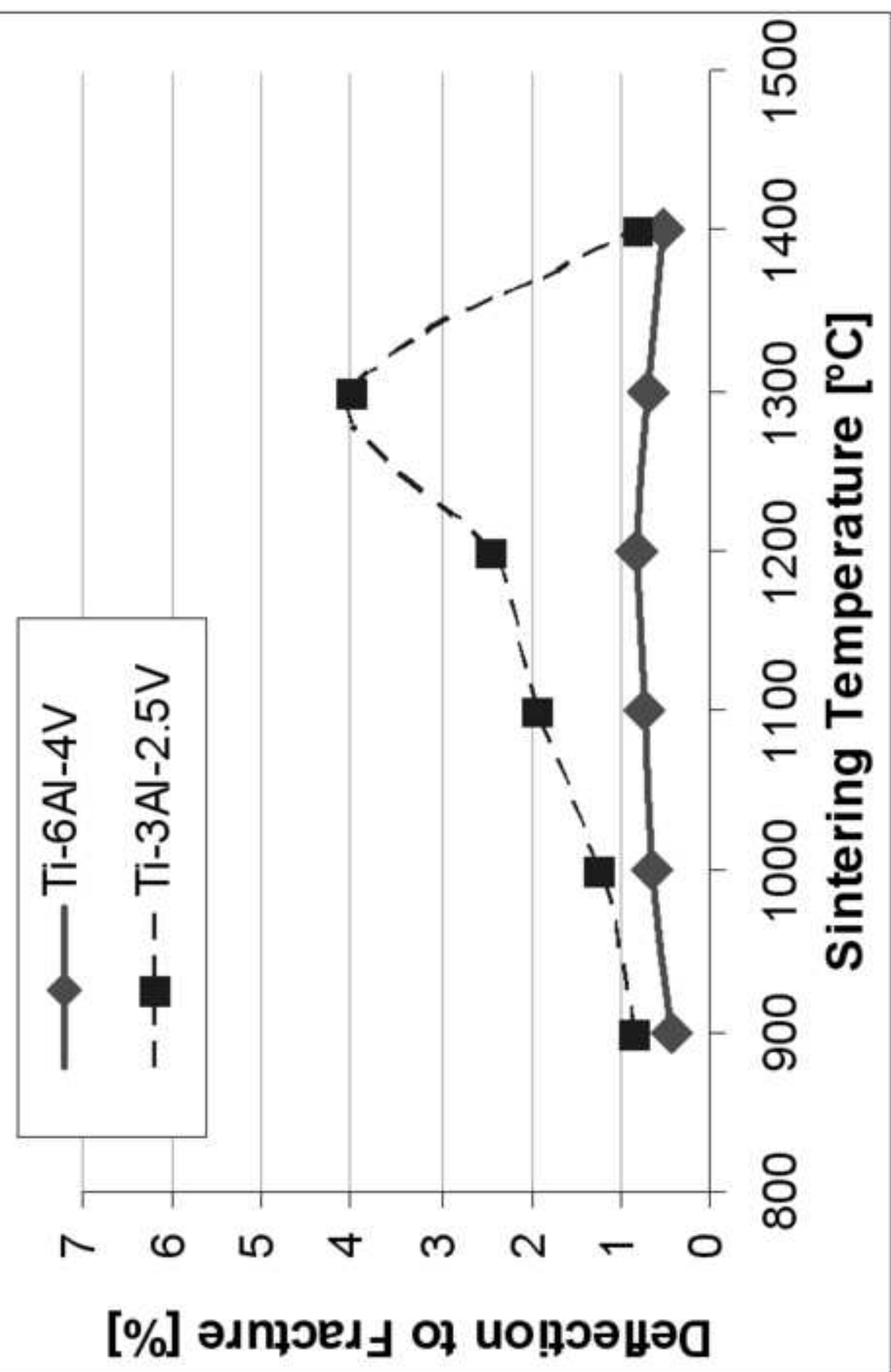




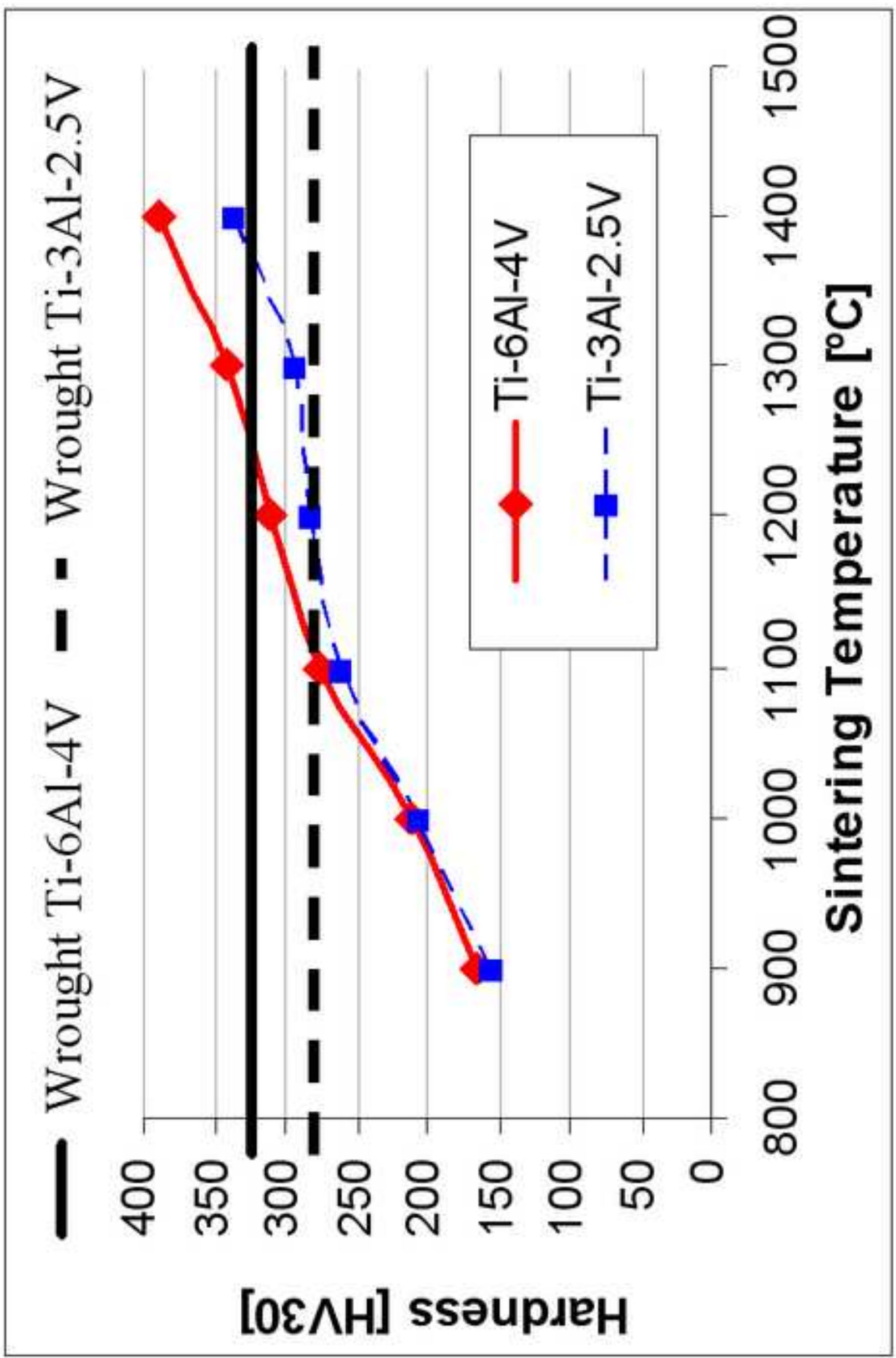




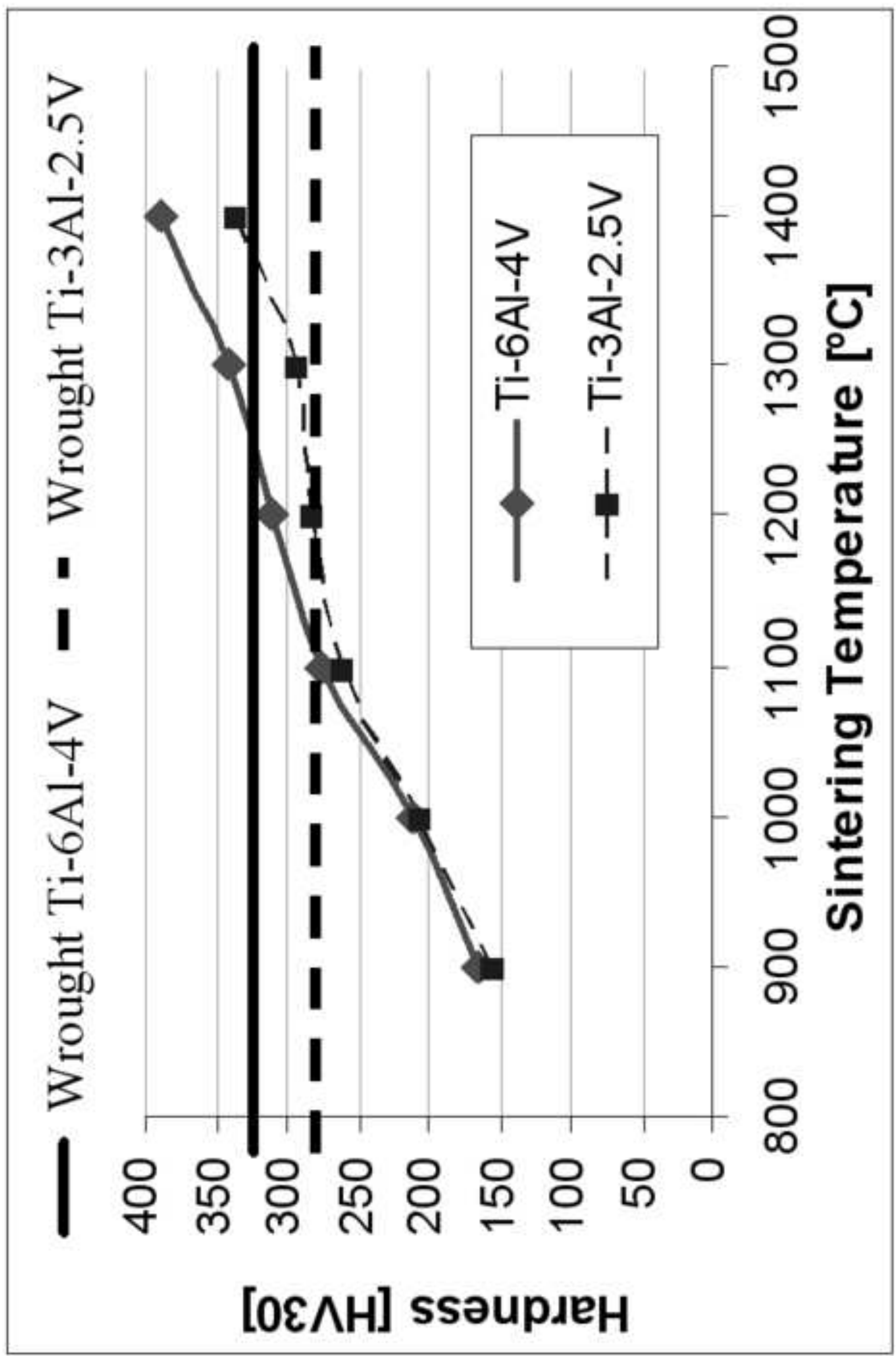

